\title{
Stimulating the Expression of Sphingosine Kinase 1 (SphK1) is Beneficial to Reduce Acrylamide-Induced Nerve Cell Damage
}

\author{
Yong-Hui Wu ( $\nabla$ wuyonghui777@163.com ) \\ Harbin Medical University https://orcid.org/0000-0002-4838-2947 \\ Sheng-Yuan Wang \\ Harbin Medical University
}

Xiao-Li Wang

Harbin Medical University

Rui Xin

Harbin Medical University

Ye Xin

Harbin Medical University

Rui Wang

Harbin Medical University

Kun Ma

Harbin Medical University

Cui-Ping Yu

Harbin Medical University

Dan Zhang

Harbin Medical University

Xiao-Rong Zhou

Harbin Medical University

Wei-Wei Ma

Harbin Medical University

Chao Wang

Harbin Medical University

\section{Research}

Keywords: Acrylamide, SphKI, Neurotoxicity, Apoptosis, MAPK pathway

Posted Date: September 28th, 2020

DOl: https://doi.org/10.21203/rs.3.rs-80914/v1 
License: (c) (i) This work is licensed under a Creative Commons Attribution 4.0 International License. Read Full License 


\section{Stimulating the expression of sphingosine kinase 1 (SphK1) is beneficial to reduce acrylamide-induced nerve cell damage}

Sheng-Yuan Wang ${ }^{1}$, Xiao-Li Wang ${ }^{1}$, Rui Xin ${ }^{1}$, Ye Xin ${ }^{1}$, Rui Wang ${ }^{1}$, Kun $\mathrm{Ma}^{2}$, Cui-Ping $\mathrm{Yu}^{1}$, Dan Zhang ${ }^{1}$, Xiao-Rong Zhou ${ }^{1}$, Wei-Wei Ma ${ }^{3}$, Chao $\mathrm{Wang}^{4}$, Yong-Hui Wu ${ }^{1 *}$

${ }^{1}$ Department of Occupational Health, Public Health College, Harbin Medical University, Harbin, P. R.

${ }^{2}$ Department of Hygienic Toxicology, Public Health College, Harbin Medical University, Harbin, P. R.

${ }^{3}$ Harbin Railway Center for Disease Control and Prevention, Harbin, P. R.

${ }^{4}$ Health Commission of Heilongjiang Province.

* Address correspondence to this author at: The Department of Occupational Health, Public Health College, Harbin Medical University, 157 Baojian Road, Nan gang District, Harbin, People’s Republic of China 150086. Phone: +86-451-8750-2827, Fax: +86-451-8750-2827, E-mail:wuyonghui777@,163.com. 


\section{Abstract}

Background: Sphingosine kinase $1(\mathrm{SphKl})$ is the main rate-limiting enzyme that catalyzes the production of sphingosine 1-phosophate (S1P) from sphingosine (Sph). It has a certain role in the protection of nerve damage. However, the role of acrylamide (ACR) in nerve damage is currently unclear.

Methods: In our current research, liquid chromatography triple quadrupole tandem mass spectrometer (LC-MS/MS) and reverse transcription-PCR (RT-qPCR) were used to detect S1P content in serum and SphK1 content in whole blood in the ACR contact and non-contact groups. In vitro experiments, SphK1 in human neuroblastoma cell (SH-SY5Y) was activated by adding SphK1 specific activator phorbol 12-myristate 13-acetate (PMA). Our research adopted cell viability assay, flow cytometry, western blot, RT-qPCR and related protein detection at mitogen activated protein kinases (MAPK) signaling pathway. The results of the population study showed that the contents of SphKl and S1P in the ACR contact group were lower than those in the non-contact group.

Results: The results of the population study showed that the contents of SphKl and S1P in the ACR contact group were lower than those in the non-contact group. The results of in vitro experiments showed that the expression of SphKl decreased with the increase of ACR concentration. Activating SphK1 can improve the survival rate of SH-SY5Y cells and decrease the apoptosis rate. Activating SphK1 in SH-SY5Y cells can regulate MAPK signaling, including enhancing the phosphorylation of extracellular signal-regulated protein kinases (ERK) and inhibiting the phosphorylation of c-Jun N-terminal kinases (JNK) and p38.

Conclusion: These results suggest that activating SphKl can protect the nerve cell damage caused by ACR. This study will provide new ideas for the prevention of neurological damage caused by ACR.

Key words: Acrylamide; SphKl; Neurotoxicity; Apoptosis; MAPK pathway 


\section{Background}

Acrylamide (ACR) is a water-soluble vinyl monomer and mainly used to synthesize polyacrylamide in industry. With the widespread use of polyacrylamide, workers contact to acrylamide monomers and scientific researchers in molecular biology laboratories are increasing. The exposure of the population to ACR is multi-channel. Staff intake it by Skin in the occupational environment ${ }^{[1]}$ and the general population by smoking ${ }^{[2]}$, drinking water ${ }^{[3]}$ and food ${ }^{[4]}$. Acrylamide tends to accumulate in brain tissue and other fat-rich parts. Although the accumulated content is small, the harmful effect is huge. Therefore, the neurotoxicity of acrylamide has caused widespread concern among researchers.

A large number of in vivo and in vitro studies have shown that acrylamide can cause neurotoxicity, reproductive toxicity, genotoxicity and carcinogenicity in animals, but only the neurotoxicity has been found in the population ${ }^{[5-9]}$. At present, there are many possible mechanisms for neurotoxicity caused by ACR, including inhibition of rapid neuraxon transport, changes in levels and functions of neurotransmitters, inhibition of energy metabolism in the central nervous system, oxidative stress etc ${ }^{[10-13]}$. In addition, promoting apoptosis may also be a potential neurotoxicity mechanism of ACR. Lakshmi et al. found that acrylamide can cause nuclear shrinkage and degeneration of some neurons in the rat cortex. The degenerated neurons in the low-dose group have a tendency to apoptosis, which may be in the early stage of apoptosis ${ }^{[14]}$. A recent study found that acrylamide can cause apoptosis in rat brain cells ${ }^{[15]}$. However, the mechanism of acrylamide-induced apoptosis is currently unclear.

Sphingolipid is a type of lipid that can be converted to each other and has biological activity, which is an important part of the structure and function of biofilm ${ }^{[16]}$. Its metabolites ceramide (Cer), sphingosine (Sph) and sphingosine 1-phosphate (S1P) have been shown to be the main 


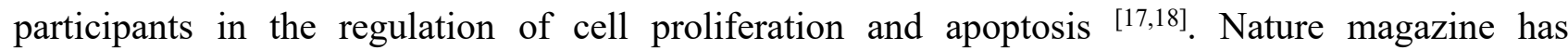
confirmed that there is a dynamic balance between Cer, Sph and S1P in the cell, which directly determines the survival of the cell ${ }^{[19]}$. Therefore, Boslem et al. referd to this balanced relationship formed by Cer, Sph and S1P as "sphingomyelin rheostat" [20]. Sphingosine kinase (SphK) is the key enzyme to maintain this balance.

Sphingosine kinase $(\mathrm{SphK})$ is the main rate-limiting enzyme that catalyzes the production of sphingosine (Sph) to sphingosine 1-phosophate (S1P) and it is also an important signal transduction for cell proliferation and survival molecule ${ }^{[21]}$. Sphingosine kinase expresses two subtypes in the human body, namely sphingosine kinase 1 (SphK1) and sphingosine kinase 2 (SphK2). Compared with SphK2, SphK1 does not include any transmembrane domain and is widely distributed in different tissues of humans and animals. SphK1 plays an important role in regulating inflammation, autophagy, cell proliferation, differentiation, migration and apoptosis ${ }^{[22]}$. SphK1 mainly exists on the cytoplasm and various stimuli under normal physiological conditions, such ascytokines and growth factors activating mitogen-activated protein kinase (MAPK), SphK1 is activated and transferred from the cytoplasm to the plasma membrane for its sphingosine conversion to S1P ${ }^{[23]}$. SphK1 has an effect on the MAPK pathway. MAPK is a kind of serine/threonine protein kinase, which acts on the nucleus and can activate many transcription factors after it activated.

Our previous animal metabolomics studies have shown that S1P exists in the serum metabolites of rats after ACR exposure, and shows a low expression status. Adding protective agent during ACR exposure, the expression intensity of S1P increases with the concentration of protective agent ${ }^{[24]}$. Afterwards, we conducted a metabolomics analysis of the serum of the acrylamide occupational population, and the results showed that Sph was present and highly expressed in the serum metabolites ${ }^{[25]}$. These changes are inseparable from the regulation of SphK1 activity. 
In this study, we used liquid chromatography triple quadrupole tandem mass spectrometer (LC-MS/MS) and reverse transcription-PCR (RT-qPCR) to detect S1P content in serum and SphK1 content in whole blood in the ACR contact and non-contact groups. Meanwhile, using acrylamide as the test substance, we analyzed the role of activated SphK1 in acrylamide-induced SH-SY5Y cell damage and its effect on apoptosis. This study is the first to explore the role of SphK1 in nerve damage caused by acrylamide at home and abroad. Its main purpose is to provide better prevention and treatment methods for the nervous system damage in the occupational population of acrylamide and to provide new ideas for the prevention of nervous system damage caused by acrylamide.

\section{Results}

\section{The role of SphK in ACR-induced nerve cell damage}

The SphK family includes two subtypes of SphK1 and SphK2. In this study, we performed Western blot detection on these two subtypes in SH-SY5Y cells infected with ACR to observe the role of these two subtypes. Western blot results showed that the expression of SphK1 decreased with the increase of the exposure concentration in SH-SY5Y cells infected with acrylamide (Figure 1A and Figure 1B); while the expression of SphK2 did not change with the increase of exposure concentration in SH-SY5Y cells infected with acrylamide (Figure 1A and Figure1C).

\section{Subject characteristics}

Study participants contact to ACR were employed in two ACR workshops in the refining factory. Both workshops produced only ACR monomer and no other ACR-related products ${ }^{[25,26]}$. Demographic data for the study participants are provided in Table 1. In total, 60 subjects were recruited to the study: the contact group $(n=30$; age, $41.63 \pm 1.67$ years $)$ and the non-contact group ( $n=30$; age, $41.13 \pm 1.41$ years). There were no statistical differences in age, work years, sex, smoking habits, alcohol consumption, preference for fried food or coffee consumption between the 
two group (Table 1). All members of the contact group wore personal protective equipment, such as disposable latex gloves and dust masks.

Measurement of ACR levels in the production workshops was carried out in accordance with the Chinese National Standard for Exposure Limits (GBZ 159). ACR levels were measured in the morning and afternoon for three consecutive days ${ }^{[25,26]}$. The concentration of ACR at four sampling points in the production workshop was $<8.3 \times 10^{-4} \mathrm{mg} / \mathrm{m}^{3}$ (Supplementary Table 4). These levels are within the limits of the Chinese health and safety guidelines (permissible concentration-time weighted average (PC-TWA), $0.3 \mathrm{mg} / \mathrm{m}^{3}$ ).

\section{The content of S1P in human serum}

A standard curve is drawn with the mass concentration $(\mathrm{ng} / \mathrm{mL})$ as the abscissa and the peak area as the ordinate. The standard curve equation of $\mathrm{S} 1 \mathrm{P}$ is $\mathrm{Y}=0.000305049 \mathrm{X}-0.000370314$, the correlation coefficient is $\left(r^{2}=0.995092\right)$ (Figure $\left.2 \mathrm{~A}\right)$. The results of this study show that this method has a good linear relationship which a correlation coefficient is more than 0.99 . The results using this method are accurate and reliable. LC-MS/MS detection of S1P in the serum of ACR contact group and non-contact group showed that the content of S1P in serum in ACR contact group $(520.01 \pm 111.76 \mathrm{ng} / \mathrm{mL})$ was significantly lower than that in non-contact group $(637.64 \pm 143.63$ $\mathrm{ng} / \mathrm{mL}$ ) (Figure 2B and Figure 2C) .

\section{Expression of SphK1 in whole blood of the population}

In this study, RT-qPCR fluorescence quantitative method was used to detect the transcription level of SphK1 gene in whole blood of ACR contact group and non-contact group. When RT-qPCR fluorescence quantitative method was used to detect the relative expression level of SphK1 mRNA, the dissolution curves of SphK1 gene and internal reference $\beta$-actin gene met the RT-qPCR fluorescence quantitative detection standard (Figure 3A and Figure 3B). RT-qPCR results showed 
that the relative expression of SphK1 mRNA in the ACR contact group was lower than that in the non-contact group (Figure 3C).

\section{Determination of the activation efficiency of SphK1 by PMA}

In this study, we used the SphK1 specific activator named PMA to activate SphK1 expression in SH-SY5Y cells. Therefore, we call the normal cell with PMA as the NC group and the normal cells without PMA as the control group. RT-qPCR results showed that the relative expression of SphK1 mRNA in NC group was higher than that in control group after adding PMA to normal SH-SY5Y cells (Figure 4A). Western blot results showed that the SphK1 protein expression in the NC group was higher than that in the control group after adding PMA to normal SH-SY5Y cells (Figure 4B and Figure 4C).

\section{Expression of SphK1 in SH-SY5Y cells of each group}

RT-qPCR results showed that compared with the NC group, the relative expression of SphK1 mRNA in the cells of the experimental group and the SphK1 activator group decreased with the increase of the concentration; compared with the experimental group, the relative expression of SphK1 mRNA in the cells of the activator group increased at the same ACR concentration (Figure 5A) .Western blot results showed that compared with the NC group, the expression of SphK1 protein in the cells of the experimental group and the SphK1 activator group decreased with the increase of the concentration; compared with the experimental group, the expression of SphK1 protein in the cells of the SphK1 activator group increased at the same ACR concentration (Figure 5B and Figure 5C).

\section{Fluorescence intensity of SphK1 in each group of SH-SY5Y cells}

To determine the role of SphK1 in ACR-induced nerve cell damage, we used immunofluorescence to detect the expression of SphK1 in the experimental group and the SphK1 
activator group. Compared with the NC group, the SphK1 fluorescence expression intensity decreased in both the experimental group and the SphK1 activator group (Figure 6A and Figure 6B). At the same ACR concentration, compared with the experimental group, the SphK1 fluorescence expression intensity increased in the SphK1 activator group (Figure 6A and Figure 6B). This indicated that ACR caused a decrease in SphK1 expression during the process of damaging nerve cells.

\section{Effect of SphK1 on the relative growth and survival rate of SH-SY5Y cells}

Observing the morphology of SH-SY5Y cells in each group after ACR exposure through a microscope, it can be found that compared with the NC group, the number of cells in the experimental group and the SphK1 activator group decreases with the increase of the ACR concentration, and the cell morphology appears shrinkage, rounding and rupture (Figure 7A). However, compared with the experimental group, the number of cells in the SphK1 activator group increased significantly at the same ACR concentration $(1.25 \mathrm{mM}$ and $2.5 \mathrm{mM})$, and the cell morphology showed shrinkage, rounding and rupture cells are reduced (Figure 7A).

The relative growth and survival rates of the cells in the experimental group and SphK1 activator group after ACR exposure were lower than those in the NC group. Compared with the NC group, the relative cell growth and survival rate of the experimental group $(1.25 \mathrm{mM}$ and $2.5 \mathrm{mM})$ and the SphK1 activator group $(2.5 \mathrm{mM})$ were statistically significant (Figure $7 \mathrm{~B})$.When the concentration of the SphK1 activator group was $1.25 \mathrm{mM}$, the relative growth and survival rate of the cells was not stats tically significant compared with the NC group. The relative growth and survival rate of cells in the SphK1 activator group were higher than those in the experimental group with the same concentration (1.25mM and 2.5mM) (Figure 7B).

\section{Effect of SphK1 on apoptosis}


After ACR exposure, the apoptosis rate of the experimental group and the SphK1 activator group increased with the increase of the concentration. The apoptosis rates of the experimental group at the concentration of $1.25 \mathrm{mM}$ and $2.5 \mathrm{mM}$ were respectively $3.06 \% \pm 0.13$ and $6.86 \% \pm 0.67$, while the apoptosis rates in the SphK1 activator group at the concentration of $1.25 \mathrm{mM}$ and $2.5 \mathrm{mM}$ were respectively $2.12 \% \pm 0.33$ and $3.53 \% \pm 0.17$. Compared with the $\mathrm{NC}$ group, the apoptosis rates of the experimental group and the SphK1 activator group were both statistically significant $(p<0.05)$. The apoptosis rate of the SphK1 activator group was lower than that of the experimental group at the same ACR concentration (1.25mM and 2.5mM) (Figure 8).

\section{Effect of SphK1 on MAPK signaling pathway}

Western blot was used to analyze the effect of SphK1 on ERK1/2, JNK and p38 MAPK signaling pathways after ACR-infected SH-SY5Ycells. Western blot results showed that compared with the $\mathrm{NC}$ group, with the increase of the concentration of exposure, the phosphorylation of JNK and p38 in the experimental group and the SphK1 activator group was significantly increased, while the phosphorylation of ERK1/2 was significantly decreased in the experimental group and the SphK1 activator group (Figure 9). Compared with the experimental group at the same ACR concentration, the phosphorylation of JNK and p38 in the SphK1 activator group was significantly reduced, while the phosphorylation of ERK1/2 was significantly increased (Figure 9).

\section{Discussion}

There are a total of seven isozymes in the SphKs family. Among the seven isozymes, SphK1 and SphK2 which come from mammals originate from humans and mice ${ }^{[27-29]}$. Studies have shown that sphingosine kinase only expresses two subtypes of SphK1 and SphK2 in the human body, these two isozymes belong to diacylglycerol kinase ${ }^{[30]}$. Although both are stored in the cytoplasm, there are significant differences in the phase of expression. SphK1 is mainly expressed in human lungs and 
brain, while SphK2 is mainly expressed in human heart and liver ${ }^{[31]}$. SphK1 plays a role in promoting the survival and growth of cells, while SphK2 can promote the apoptosis of various cells and inhibit their proliferation process. Therefore, SphK1 and SphK2 each play a different biological function.

In our current research, we used Western blot to detect the two subtypes in ACR-infected SH-SY5Y, which observe the role of SphK1 and SphK2 in those cells. The results of this study indicated that the expression level of SphK1 decreases as the concentration of infection increases, while the expression level of SphK2 does not change. This shows that SphK1 has some effects in the process of ACR-induced SH-SY5Y cell damage, while SphK2 does not play a role in this process.

SphK1 is an important enzyme for sphingolipid metabolism in the body, which is very important for maintaining the steady state between Cer, Sph and S1P. In the previous population metabolomics study, Sph was found in the serum metabolites of the acrylamide occupational population and was highly expressed. Therefore, in order to verify the accuracy of our previous research results, as well as to determine the expression level of SphK1 in the ACR exposure group and the expression level of S1P, we determined the content of SphK1 in whole blood and S1P in serum among occupational groups.

RT-qPCR results showed that the relative expression of SphK1 mRNA in the ACR contact group was lower than that in the non-contact group. LC-MS/MS results showed that the content of S1P in serum in ACR contact group $(520.01 \pm 111.76 \mathrm{ng} / \mathrm{mL})$ is significantly lower than that in the non-contact group $(637.64 \pm 143.63 \mathrm{ng} / \mathrm{mL})$. Therefore, the results of this study strongly confirmed that due to the low expression of SphK1, the Sph level increased and the S1P level decreased in the ACR contact group. This indicated that SphK1 may play a key role in the process of nerve damage 
caused by ACR, and this effect may directly lead to the neurotoxic effect of ACR on the professional population. Therefore, this study then conducted vitro experiments to determine the role of SphK1 in ACR-induced nerve cell damage.

Studies have shown that PMA can induce the activation of SphK1 gene in human megakaryocytic cell line MEG-O1 and rat pheochromocytoma PC12 cell ${ }^{[33-35]}$. Therefore, we measured efficiency of PMA on SphK1 activation in SH-SY5Y cells. The results of this study showed that after adding PMA to normal SH-SY5Y cells, the NC group was higher than the control group in terms of the relative expression of SphK1 mRNA and SphK1 protein. This showed that PMA has a specific activation effect on SphK1, which can replace traditional transfection methods for subsequent research.

In this study, we tested the mRNA and protein of SphK1 in the experimental group and the SphK1 activator group, and measured the fluorescence intensity of SphK1 in each group by immunofluorescence to verify whether there was a dose responsive relation between that and the concentration of ACR. The results of this study indicated that with the increase of the concentration of SphK1, the expression level and fluorescence intensity decreased. In the same concentration of ACR, compared with the experimental group, the expression level and fluorescence intensity of SphK1 in the SphK1 activator group increased. This showed that there is a dose response relation between SphK1 and toxic dosage in ACR-infected nerve cells, and activated SphK1 may affect the toxic effect of ACR on nerve cells.

Studies have shown that activating SphK1 expression can improve the occurrence of different neurological diseases, including Alzheimer's disease ${ }^{[36]}$, Huntington's disease ${ }^{[37]}$, cerebral ischemic reperfusion injury ${ }^{[38]}$ and Parkinson's disease ${ }^{[39]}$. In this study, the relative growth and survival rates of cells in the experimental group and the SphK1 activator group were lower than those in the NC 
group. In the same ACR concentration, the relative growth and survival rates of cells in the SphK1 activator group were higher than that in the experiment group. This indicated that activating SphK1 expression can increase the survival rate of nerve cells and reduce the damage of ACR to nerve cells.

Studies have shown that high dose of acrylamide can cause apoptosis of glial cells, including rat primary astrocytes and human astrocytoma cell lines ${ }^{[40]}$. A recent study showed that ACR can cause apoptosis of rat brain cells ${ }^{[41]}$. SphK1 can control the apoptosis of cells by regulating the MAPK pathway. That pathway mainly includes three signal pathways, including JNK, p38 and ERK1/2, all of which can participate in the pathological process of neurodegenerative diseases ${ }^{[42]}$. Studies have shown that SphK1 and S1P played an important role in stimulating the anti-apoptotic MAPK cascade and inhibiting the pro-apoptotic MAPK cascade ${ }^{[43]}$. Therefore, SphK1 plays an important role in the regulation of cell survival and apoptosis.

Studies have shown that ACR induced the apoptosis of nerve cells by inhibiting ERK1/2 and activating JNK and p38. The results of this study showed that the phosphorylation of JNK and p38 was signicantly reduced, while the phosphorylation of ERK1/2 was significantly enhanced in the SphK1 activator group at the same concentration. The results of flow cytometry showed that the apoptosis rate in the SphK1 activator group was lower than that in the experimental group at the same concentration. This showed that activating SphK1 helped to reduce the apoptosis effect of ACR on nerve cells and had a protective effect in the process of nerve cell apoptosis caused by ACR.

\section{Conclusions}

This study is the first to show that the low expression of SphK1 in the ACR professional population leads to the increase of Sph and the decrease of S1P, which may directly lead to the 
neurotoxic effect of ACR on the occupational population. The results of in vitro experiments show that activating Sphk1 can significantly increase the survival rate of nerve cells and reduce the apoptosis by ACR through the regulation of MAPK signal pathways, which improves the nerve damage caused by ACR. This study is the first to investigate the role of SphK1 in ACR-induced nerve injury. It will lay the foundation for revealing the mechanism of nervous system damage caused by ACR and achieve better prevention and treatment of neurological injury in ACR occupational population. It provides new ideas for the prevention of nervous system damage caused by ACR.

\section{Methods}

\section{Chemicals, Reagents and Antibodies}

Acrylamide (ACR) (99.9 \% purity) was purchased from Amresco Co. Phorbol 12-myristate 13-acetate (PMA), dimethylsulfoxide (DMSO), sphingosine 1-phosophate (S1P) standard, 4\% paraformaldehyde were purchased from Sigma Chemical Co. Chromatographically pure methanol, acetonitrile, and formic acid were form Thermo Fisher Scientific Co. Culture medium RPMI-1640 and fetal bovine serum (FBS) were obtained from HyClone Co. Primary antibodies against extracellular signal regulated protein kinase (ERK1/2), p-ERK1/2, c-Jun N-terminal kinase (JNK), p-JNK, p38 mitogen-activated protein kinases (p38), p-p38, and internal reference glyceraldehyde-3-phosphate (GAPDH) were purchased from Cell Signaling Technology. SphK1 and Sphingosine kinase $2(\mathrm{SphK} 2)$ antibodies were purchased form Abcam Co. Antibody against neuronal (NeuN), FITC-conjugated goat anti-mouse IgG secondary antibody, and Cy3-conjugated goat anti-rabbit IgG secondary antibody were purchased Origene Co. RT-qPCR assay kit was purchased Toyobo Co. DAPI dye, BCA protein assay kit, cell counting kit-8 (CCK-8), and AnnexinVFITC/ propidiumiodide (PI) apoptosis detection kit were from Beyotime Institute of 
Biotechnology (Shanghai, China).

\section{Study subjects}

We take the occupational group who is contact to acrylamide in the acrylamide workshop of a petroleum refining plant in northern China as the contact group, and the non-contact group for those who are not contact to acrylamide at the plant. We tested the concentration of acrylamide in the production workshop of the plant. In addition, the basic conditions, sanitary protection measures and personal protective equipment of the factory are investigated; unified questionnaires are used to record the general conditions, occupational history and personal protection of the respondents. Personnel surveys and questionnaire filling are completed in a face-to-face manner to ensure which each respondent can complete the questionnaire independently and seriously, which reduced the bias of the survey results. The study was approved by the Ethical Committee of the Harbin Medical University and informed consent was obtained from all subjects ${ }^{[25,26]}$. The exclusion criteria of the research object: exclude the object with long-term use of antipsychotic drugs, the object with the central nervous system function affected by internal medicine systemic disease. Rule out metabolic disorders of metabolites eventually in the blood and other diseases, and diabetic patients with long-term use of drugs ${ }^{[25,26]}$.

In total, 60 subjects were recruited to the study: the contact group $(n=30$; age, $41.63 \pm 1.67$ years; work years, $14.93 \pm 5.08$ years $)$ and the non-contact group $(\mathrm{n}=30$; age, $41.13 \pm 1.41$ years; work years, $13.87 \pm 3.26$ years) (Table 1$)$.

\section{Whole blood and serum collection}

The two groups the same dietary intake and were prohibited from drinking alcohol during the first 3 days of urine sampling. Venous blood samples $(4 \mathrm{~mL})$ were collected in the morning before breakfast using a vacuum heparin anticoagulant extraction tube system. We taken $1 \mathrm{~mL}$ from the 
collected whole blood into $2 \mathrm{~mL}$ centrifuge tubes, and then quick-freezen inliquid nitrogen, at last stored at $-80{ }^{\circ} \mathrm{C}$ until analysis. Surplus blood samples were immediately centrifuged at $3,000 \times g$ for $10 \mathrm{~min}$ at room temperature. The serum was separated and stored at $-80^{\circ} \mathrm{C}$ until analysis.

\section{LC-MS/MS detection of S1P in serum}

S1P standard product was precisely weighed $1 \mathrm{mg}$ into a weighing bottle, and deionized water was added to obtain stock solution with mass concentration of $1 \mathrm{mg} / \mathrm{mL}$. Then working fluids were prepared with S1P whose mass concentration of $20,50,100,200,500,1000 \mathrm{mg} / \mathrm{mL}$ using methanol and stock solution, and a standard curve was drawn. The serum sample was removed from the refrigerator at $-80{ }^{\circ} \mathrm{C}$ and thawed it at room temperature. $50 \mu \mathrm{L}$ of serum, $5 \mu \mathrm{L}$ of C17-S1P (interior label) and $145 \mu \mathrm{L}$ of methanol were added into a $1.5 \mathrm{~mL}$ centrifuge tube, and then mixed for $20 \mathrm{~min}$. Test sample was centrifuged for $10 \mathrm{~min}$ at $4{ }^{\circ} \mathrm{C}$ at $13,200 \mathrm{rpm}$. Supernatant was transferred to the autosampler bottle for sample detection. Chromatographic separation was accomplished by ACQUITYTM UPLC I-CLASS system (Waters Corporation, USA). The chromatographic column was HSS T3 C18 column $(100 \times 2.1 \mathrm{~mm}, 1.7 \mu \mathrm{m}$; Waters Corporation, USA). Linear gradient elution was used during the analysis. Mobile phase A was $5 \mathrm{mM}$ ammonium formate $\sim 0.1 \%$ formic acid aqueous solution, and mobile phase B was acetonitrile solution (Supplementary Table 1). The column temperature was $55^{\circ} \mathrm{C}$, and the injection volume was $5 \mu \mathrm{L}$.

Mass spectrometry analysis was completed by Xevo TQ-S Micro (Waters Corporation, USA), using positive electrospray ion source mode and multiple reaction detection scanning mode (MRM). The detection time of each sample was $5 \mathrm{~min}$. The ion source temperature was $150{ }^{\circ} \mathrm{C}$ and the desolvation gas temperature was $500{ }^{\circ} \mathrm{C}$. The desolvation gas flow (N2) was $1100 \mathrm{~L} / \mathrm{hr}$, and the cone flow (N2) was $10 \mathrm{~L} / \mathrm{hr}$. The positive ion capillary voltage was $2800.0 \mathrm{~V}$ and the cone voltage was $25.0 \mathrm{~V}$. 


\section{Cell culturing and grouping}

Human neuroblastoma cells (SH-SY5Y) were provided by Pronocel Life Technology Co, Ltd. (Wuhan, China). Cells were inoculated in 1640 culture medium (containing 10\% fetal bovine serum, $1 \%$ double antibody), culturing at $37^{\circ} \mathrm{C}, 5 \% \mathrm{CO}_{2}$. Trypsin digestion fluid was used every two days to digest and passage.

SH-SYSY cells were divided into experimental group and SphK1 activator group. The experimental group was respectively given acrylamide solutions with final concentrations of 1.25 $\mathrm{mM}$ and $2.5 \mathrm{mM}$, and the exposure time was $24 \mathrm{~h}$. In the SphK1 activator group, on the basis of the concentration of the experimental group, each concentration was added with PMA solution [dimethyl sulfoxide (DMSO), the final concentration was $100 \mathrm{nmol} / \mathrm{L}$ ], and other treatments were consistent with the experimental group. The control group of the experimental group and the SphK1 activator group was added PMA solution to normal SH-SY5Y cells, which is called NC group.

\section{RNA extraction and real-time qPCR analysis}

RNA was extracted from the whole blood and cell lysates using the RNA Blood Mini kit and RNeasy ${ }^{\circledR}$ Mini Kit (QIAGEN) according to the manufacturer's instructions. That RNA was Reverse transcribed using ReverTra Ace qPCR RT Kit and ReverTra Ace qPCR RT Master Mix with gDNA Remover (TOYOBO). The relative fold change in expression of the target normalized to expression of the corresponding control was calculated by the comparative Ct method. Primers are described in Supplementary Table 2 and Table 3.

\section{Cell Viability Assay}

Cell viability was indirectly evaluated by CCK-8 assay. SH-SY5Y cells in logarithmic growth phase were seeded into 96-well plates $\left(1 \times 10^{4}\right.$ cells/well $)$ and exposed to from experiment group and SphK1 activator groups at acrylamide concentrations of $1.25 \mathrm{mM}$ and $2.5 \mathrm{mM}$ for $24 \mathrm{~h}$. Each group 
included six replicates. At the end of the incubation period, $10 \mu \mathrm{L}$ of CCK- 8 solution were added into each well and incubated for $2 \mathrm{~h}$. The absorbance was read at a wavelength of $490 \mathrm{~nm}$ with a microplate reader at least three times. Cell viability was expressed as the relative survival rate calculated as the ratio of the absorbance of experiment groups and SphK1 activator groups to the absorbance of the NC group.

\section{Quantification of Apoptosis}

Cell apoptosis was analyzed using annexin V-FITC/PI apoptosis kit. Total cells $\left(1 \times 10^{6}\right.$ cells/well $)$ were collected through centrifugation and then cells were suspended in $200 \mu \mathrm{L}$ of binding buffer. Five microliters of annexin V-FITC and $10 \mu \mathrm{L}$ of PI were added to the experimental groups and SphK1 activator groups. All samples were incubated at room temperature in the dark for $15 \mathrm{~min}$. FITC-AnnexinV fluorescence was measured through FL1 channel with an emission wavelength of $530 \mathrm{~nm}$, and PI fluorescence was measured through FL3 channel with an emission wavelength of $640 \mathrm{~nm}$. The cells were analyzed using flow cytometry (BD FACS Canto ${ }^{\mathrm{TM}}$ II, San Jose, CA, USA) with Cell Quest software (BD FACS Diva ${ }^{\mathrm{TM}}$, San Jose, CA, USA).

\section{Immunocytochemistry}

After treatment for according to experimental grouping for $24 \mathrm{~h}$, SH-SY5Y cells were washed three times with phosphate buffer solution (PBS) and fixed with $4 \%$ paraformaldehyde for 30 min at room temperature. The cells were incubated with PBS containing $0.1 \%$ Triton- 100 at room temperature for $30 \mathrm{~min}$ and blocked with $2 \%$ bull serum albumin (BSA) for $30 \mathrm{~min}$. Cultures were incubated overnight at $4{ }^{\circ} \mathrm{C}$ in PBS containing rabbit anti-NeuN (1:200) and mouse anti-SphK1 (1:100) and allowed to react with Cy3 conjugated goat anti-rabbit IgG (1:200) and FITC conjugated goat anti-mouse $\operatorname{IgG}(1: 100)$ for $1 \mathrm{~h}$ in a dark room. The nucleus was stained with DAPI dye for 10 min and then washed three times with PBS. Images were captured and digitized under an inverted 
fluorescence microscope (CX41-FS, Olympus, Japan).

\section{Western Blot Analysis}

After treatment for according to experimental grouping for $24 \mathrm{~h}$, SH-SY5Y cells were lysed in RIPA lysis buffer (Beyotime Biotechnology, Shanghai, China) containing $1 \%$ PMSF. Then, the cell suspension was centrifuged for $10 \mathrm{~min}$ at $12,000 \mathrm{rpm}$ at $4{ }^{\circ} \mathrm{C}$, and the supernatant was collected. The total protein concentration was determined by the BCA Protein Assay kit (Beyotime Biotechnology, Shanghai, China). Aliquots containing $50 \mathrm{~g}$ of protein from each group were separated by $15 \%(\mathrm{w} / \mathrm{v})$ SDS-polyacrylamide gels and transferred to polyvinylidene difluoride (PVDF) membranes. The membranes were blocked with 5\% non-fat milk/BSA in Tris-Buffered Saline and Tween 20 (TBST) for $2 \mathrm{~h}$. The blots were subsequently incubated with mouse-polyclonal primary antibodies against SphK1 (1:200) and SphK2 (1:200) and rabbit-polyclonal primary antibodies against ERK1/2(1:500)、p-ERK1/2(1:500)、JNK1/2(1:500)、 p-JNK1/2(1:500) 、p-38(1:500) and p-p38(1:500) and GAPDH (1:1000) overnight at $4{ }^{\circ} \mathrm{C}$. The membranes were washed five times with TBST and incubated with secondary antibodies (goat anti-rabbit and goat anti-mouse) at 1:2000 dilutions for $2 \mathrm{~h}$ at room temperature. Target proteins were detected by using enhanced chemiluminescence detection kit and relative intensity bands were analyzed using a gel imaging analysis system. GADPH was used as an internal control.

\section{Statistical Analysis}

Epidata 3.0 software (http://www.epidata.dk) was used for data entry and analysis. Data were expressed as mean $\pm \mathrm{SD}$. GraphPad Prism7 software was used to analyze different sets of experimental data. Continuous variable data were analyzed using two groups of independent sample t-tests, non-normal distribution data were analyzed using two groups of independent sample t-tests after logarithmic transformation to form normal or nearly normal distribution data. The data were 
determined to be continuously variable by the completely random design of the two groups and the frequency distribution of c2 tests ${ }^{[25,26]}$. One-way ANOVA and correlation analysis were used for different exposure concentrations in the experimental group and the SphK1 activator group; $t$ test was used for the same exposure concentration in that two groups. A $p$ value $\leq 0.05$ indicated statistical significance. 


\section{Abbreviations}

ACR: acrylamide; SphKs: SphingosSpine; S1P: Sphingosine1-phosophate; SphK1: SphingosineKinase1; SphK2: Sphingosine Kinase2; MAPK: Mitogen-activated protein kinases; CCK-8: Cell Counting kit-8e; PMA: Phorbol 12-m yristate 13-acetate; RT-PCR: Reverse transcription-PCR; SH-SY5Y: Human-Neuroblast from neural tissue; LC-MS/MS: Liquid chromatography triple quadrupole mass spectrometer.

\section{Authors' contributions}

WYH supervised the project,designed the experiments and analyzed the data; WSY performed the experiments, prepared the figures, and wrote part of the manuscript; WXL, XY and XR contributed to the performance of the vitro experiments; WR, XR, WR and MK contributed to the performance of the population study; YCP, ZD, ZXR, MWW and WC wrote and edited themanuscript. All authors read and approved the final manuscript.

\section{Acknowledgements}

The authors thank the staff form the petroleum refining factory in northern China who provided invaluable assistance in collecting samples.

\section{Competing interests}

The authors declare that they have no conflicts of interest relating to the content of this report.

\section{Consent for publications}

Not applicable.

\section{Data availability}

The data supporting the conclusions of this article are included within the article.

\section{Ethics approval and consent to participate}

The study was approved by the Ethical Committee of the Harbin Medical University and informed 
consent was obtained from all subjects.

\section{Funding}

This study was supported by grants from the National Natural Science Foundation of China (81803207) and the University Nursing Program for Yong Scholars with Creative Talents in Heilongjiang Province (UNPYSCT-2018078).

\section{Publisher's Note}

Springer Nature remains neutral with regard to jurisdictional claims in pub-lished maps and institutional afliations. 


\section{REFERENCES}

1. Yang CT, Li HJ, Yu SF. esearch Progress on Biomarkers of Acrylamide. J Environ Health. 2011;28(10):927-929.

2. Mojska H, Gielecinska I, Cendrowski A. Acrylamide content in cigarette mainstream smoke and estimation of exposure to acrylamide from tobacco smoke in Poland. Ann Agric Environ Med. 2016;23(3):456-461.

3. Backe WJ, Yingling V, Johnson T. The determination of acrylamide in environmental and drinking waters by large-volume -injection-hydrophilic-interaction liquid chromatography and tandem mass spectrometry. J Chromatogr A. 2014;1334:72-78.

4. Wang Q, Chen X, Ren Y, Chen Q, Meng Z, Cheng J, et al. Toxicokinetics and internal exposure of acrylamide: new insight into comprehensively profiling mercapturic acid metabolites as short-term biomarkers in rats and Chinese adolescents. Arch Toxicol.2017;91(5):2107-2118.

5. Xu Y, Cui B, Ran R, Liu Y, Chen H, Kai G, et al. Risk assessment, formation, and mitigation of dietary acrylamide: current status and future prospects. Food Chem Toxicol. 2014;69:1-12.

6. Huang M, Jiao J, Wang J, Xia Z, Zhang Y. Characterization of acrylamide-induced oxidative stress and cardiovascular toxicity in zebrafish embryos. J Hazard Mater. 2018;347:451-460.

7. Motamedshariaty VS, Amel Farzad S, Nassiri-Asl M, Hosseinzadeh H. Effects of rutin on acrylamide-induced neurotoxicity. Daru. 2014;22(1):27.

8. Dobrovolsky VN, Pacheco-Martinez MM, McDaniel LP, Pearce MG, Ding W. In vivo genotoxicity assessment of acrylamide and glycidyl methacrylate. Food Chem Toxicol. 2016;87:120-127.

9. Aras D, Cakar Z, Ozkavukcu S, Can A, Cinar O. In Vivo acrylamide exposure may cause severe toxicity to mouse oocytes through its metabolite glycidamide. PLoS One. 2017;12(2):e0172026. 
10. Erkekoglu P, Baydar T. Acrylamide neurotoxicity. Nutr Neurosci. 2014;17(2):49-57.

11. Chen W, Su H, Xu Y, Jin C. In vitro gastrointestinal digestion promotes the protective effect of blackberry extract against acrylamide-induced oxidative stress. Sci Rep. 2017;7:40514.

12. Zhao M, Wang FS, Hu XS, Chen F, Chan HM. Effect of acrylamide-induced neurotoxicity in a primary astrocytes/microglial co-culture model. Toxicol In Vitro. 2017;39:119-125.

13. Marković J, Stošić M, Kojić D, Matavulj M. Effects of acrylamide on oxidant/antioxidant parameters and CYP2E1 expression in rat pancreatic endocrine cells. Acta Histochem. 2018;120(2):73-83.

14. Lakshmi D, Gopinath K, Jayanthy G, Anjum S, Prakash D, Sudhandiran G. Ameliorating effect of fish oil on acrylamide induced oxidative stress and neuronal apoptosis in cerebral cortex. Neurochem Res. 2012;37(9):1859-1867.

15. He Y, Tan D, Bai B, Wu Z, Ji S. Epigallocatechin-3-gallate attenuates acrylamide-induced apoptosis and astrogliosis in rat cerebral cortex. Toxicol Mech Methods. 2017;27(4):298-306.

16. Young MM, Takahashi Y, Fox TE, Yun JK, Kester M, Wang HG. Sphingosine Kinase 1 Cooperates with Autophagy to Maintain Endocytic Membrane Trafficking. Cell Rep. 2016;17(6):1532-1545.

17. Selvam SP, Ogretmen B. Sphingosine kinase/sphingosine 1-phosphate signaling in cancer therapeutics and drug resistance. Handb Exp Pharmacol. 2013;(216):3-27.

18. Abuhusain HJ, Matin A, Qiao Q, Shen H, Kain N, Day BW, et al. Metabolic shift favoring sphingosine 1-phosphate at the expense of ceramide controls glioblastoma angiogenesis. J Biol Chem. 2013;288(52):37355-37364.

19. Cuvillier O, Pirianov G, Kleuser B, Vanek PG, Coso OA, Gutkind S, et al. Suppression of ceramide-mediated programmed cell death by sphingosine-1-phosphate. Nature. 
1996;381(6585):800-803.

20. Boslem E, Meikle PJ, Biden TJ. Roles of ceramide and sphingolipids in pancreatic $\beta$-cell function and dysfunction. Islets. 2012;4(3):177-187.

21. Orr Gandy KA, Obeid LM. Targeting the sphingosine kinase/sphingosine 1-phosphate pathway in disease: review of sphingosine kinase inhibitors. Biochim Biophys Acta. 2013;1831(1):157-166.

22. Wang J, Badeanlou L, Bielawski J, Ciaraldi TP, Samad F. Sphingosine kinase 1 regulates adipose proinflammatory responses and insulin resistance. Am J Physiol Endocrinol Metab. 2014;306(7):E756-768.

23. Kwong EK, Li X, Hylemon PB, Zhou H. Sphingosine Kinases/Sphingosine 1-Phosphate Signaling in Hepatic Lipid Metabolism. Curr Pharmacol Rep. 2017;3:176-183.

24. Yang S, Cao C, Chen S, Hu L, Bao W, Shi H, et al. Serum Metabolomics Analysis of Quercetin against Acrylamide-Induced Toxicity in Rats. J Agric Food Chem. 2016;64(48):9237-9245.

25. Wang SY, Yu CP, Pan YL, Zhou XR, Xin R, Wang Y, et al. Metabolomics analysis of serum from subjects after occupational exposure to acrylamide using UPLC-MS. Mol Cell Endocrinol. 2017;444:67-75.

26. Wang SY, Han D, Pan YL, Yu CP, Zhou XR, Xin R, et al. A urinary metabolomic study from subjects after long-term occupational exposure to low concentration acrylamide using UPLC-QTOF/MS. Arch Biochem Biophys. 2020;681:108279.

27. Kohama T, Olivera A, Edsall L, Nagiec MM, Dickson R, Spiegel S. Molecular cloning and functional characterization of murine sphingosine kinase. J Biol Chem. 1998;273(37): $23722-23728$.

28. Nava VE, Lacana E, Poulton S, Liu H, Sugiura M. Functional characterization of human sphingosine kinase-1. FEBS Lett. 2000;473(1): 81-84. 
29. Pitson SM, D'andrea RJ, Vandeleur L, Moretti PA, Xia P. Human sphingosine kinase: purification, molecular cloning and characterization of the native and recombinant enzymes Biochem J. 2000; 350(2): 429-441.

30. Liu H, Sugiura M, Nava VE, Edsall LC, Kono K, Poulton S, et al. Molecular cloning and functional characterization of a novel mammalian sphingosine kinase type 2 isoform. J Biol Chem. 2000;275(26):19513-19520.

31. Melendez AJ, Carlos-Dias E, Gosink M, Allen JM, Takacs L. Human sphingosine kinase: molecular cloning, functional characterization and tissue distribution. Gene. 2000;251(1):19-26.

32. Su D, Cheng Y, Li S, Dai D, Zhang W, Lv M. Sphk1 mediates neuroinflammation and neuronal injury via TRAF2/NF- $\kappa \mathrm{B}$ pathways in activated microglia in cerebral ischemia reperfusion. J Neuroimmunol. 2017;305:35-41.

33. Murate T, Banno Y, T-Koizumi K, Watanabe K, Mori N, Wada A, et al. Cell type-specific localization of sphingosine kinase 1a in human tissues. J Histochem Cytochem. 2001;49(7): $845-855$.

34. Nakade Y, Banno Y, T-Koizumi K, Hagiwara K, Sobue S, Koda M, et al. Regulation of sphingosine kinase 1 gene expression by protein kinase $\mathrm{C}$ in a human leukemia cell line, MEG-O1. Biochim Biophys Acta. 2003;1635(2-3): 104-116.

35. Sobue S, Hagiwara K, Banno Y, Tamiya-Koizumi K, Suzuki M, Takagi A, et al. Transcription factor specificity proein $1(\mathrm{Sp} 1)$ is the main regulator of nerve growth factor-induced sphingosine kinase 1 gene expression of the rat pheochromocytoma cell line, PC12. J Neurochem. 2005;95(4): 940-949.

36. Lee JY, Han SH, Park MH, Baek B, Song IS, Choi MK, et al. Neuronal SphK1 acetylates COX2 and contributes to pathogenesis in a model of Alzheimer's Disease. Nat Commun. 
2018;9(1):1479.

37. Di Pardo A, Pepe G, Castaldo S, Marracino F, Capocci L, Amico E, et al. Stimulation of Sphingosine Kinase 1 (SPHK1) Is Beneficial in a Huntington's Disease Pre-clinical Model. Front Mol Neurosci. $2019 ; 12: 100$.

38. Liu H, Zhang Z, Xu M, Xu R, Wang Z, Di G. K6PC-5 Activates SphK1-Nrf2 Signaling to Protect Neuronal Cells from Oxygen Glucose Deprivation/Re-Oxygenation. Cell Physiol Biochem. 2018;51(4):1908-1920.

39. Zhao P, Yang X, Yang L, Li M, Wood K, Liu Q, et al. Neuroprotective effects of fingolimod in mouse models of Parkinson's disease. FASEB J. 2017;31(1):172-179.

40. Lee JG, Wang YS, Chou CC. Acrylamide-induced apoptosis in rat primary astrocytes and human astrocytoma cell lines. Toxicol In Vitro. 2014;28(4):562-570.

41. He Y, Tan D, Bai B, Wu Z, Ji S. Epigallocatechin-3-gallate attenuates acrylamide-induced apoptosis and astrogliosis in rat cerebral cortex. Toxicol Mech Methods. 2017;27(4):298-306.

42. Kim EK, Choi EJ. Compromised MAPK signaling in human diseases: an update. Arch Toxicol. 2015;89(6):867-882.

43. Ho PJ, Chou CK, Yeh SF. Role of JNK and p38 MAPK in Taiwanin A-induced cell death. Life Sci. 2012;91(25-26):1358-1365.

44. Pan X, Yan D, Wang D, Wu X, Zhao W, Lu Q, et al. Mitochondrion-Mediated Apoptosis Induced by Acrylamide is Regulated by a Balance Between Nrf2 Antioxidant and MAPK Signaling Pathways in PC12 Cell. Mol Neurobiol. 2017;54(6):4781-4794. 


\begin{tabular}{|c|c|c|c|}
\hline Parameter & Contact group $(\mathrm{n}=30)$ & $\begin{array}{l}\text { Non-contact } \\
\text { group }(\mathrm{n}=30)\end{array}$ & $p$ \\
\hline \multicolumn{4}{|l|}{ Personal characteristics ${ }^{\mathrm{a}}$, mean $\pm \mathrm{SD}$} \\
\hline Age(years) & $41.63 \pm 1.67$ & $41.13 \pm 1.41$ & 0.228 \\
\hline Work years(years) & $14.93 \pm 5.08$ & $13.87 \pm 3.26$ & 0.353 \\
\hline Use of personal protective equipment, $n(\%)$ & $30(100)$ & - & \\
\hline \multicolumn{4}{|l|}{ Gender $^{\mathrm{b}}, \mathrm{n}(\%)$} \\
\hline Male & $23(76.67)$ & $24(80.00)$ & 0.754 \\
\hline \multicolumn{4}{|l|}{ Habitual status, $\mathrm{n}(\%)$} \\
\hline \multicolumn{4}{|l|}{ Smoking ${ }^{\mathrm{b}}$} \\
\hline Yes & $18(60.00)$ & $20(66.67)$ & 0.592 \\
\hline \multicolumn{4}{|l|}{ Alcohol consumption ${ }^{\mathrm{b}}$} \\
\hline Yes & $19(63.33)$ & $14(46.67)$ & 0.194 \\
\hline \multicolumn{4}{|l|}{ preference for fried food ${ }^{b}$} \\
\hline Yes & $27(90.00)$ & $29(96.67)$ & 0.301 \\
\hline \multicolumn{4}{|l|}{ coffee consumption ${ }^{\mathrm{b}}$} \\
\hline Yes & $19(63.33)$ & $21(70.00)$ & 0.584 \\
\hline
\end{tabular}

\footnotetext{
${ }^{\text {a }}$ Parameter values of contact group and non-contact group were compared using t-test.

${ }^{b}$ Parameter values of contact group and non-contact group were compared using $\chi^{2}$ test.
} 
(A)

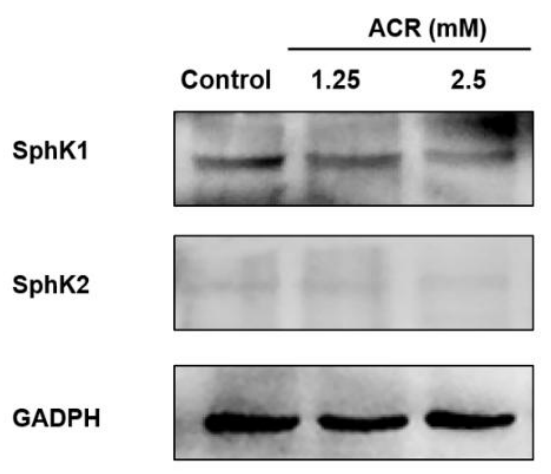

(B)

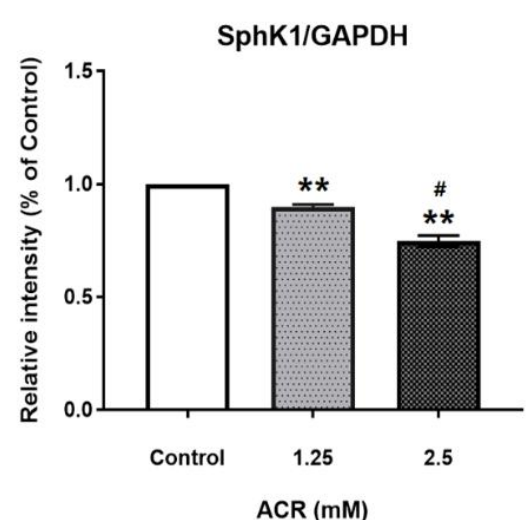

(C)

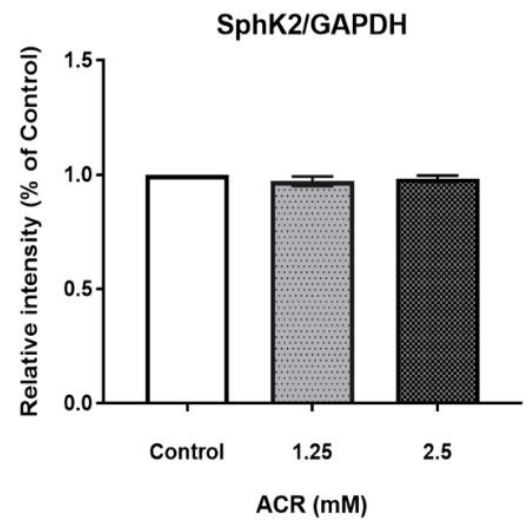

Figure 1. Western blot was used to determine the protein expression of SphK1 and SphK2 in SH-SY5Y cells exposed to ACR. (A) Protein expression of SphK1 and SphK2 in ACR-infected SH-SY5Y cells; (B) (C) Relative expression levels of SphK1 and SphK2 proteins in ACR-infected SH-SY5Y cells. Data are expressed as mean \pm $\mathrm{SD}$ (n=3 per group). ${ }^{* *} p<0.01$ versus the control group, ${ }^{\sharp} p<0.05$ versus the $1.25 \mathrm{mM}$ group. 
(A)

Compound name: S1P

Correlation coefficient: $r=0.997543, r^{\wedge} 2=0.995092$

Calibration curve: $0.000305049 * x+-0.000370314$

Response type: Internal Std ( Ref 4 ), Area * (IS Conc. / IS Area)

Curve type: Linear, Origin: Exclude, Weighting: 1/x, Axis trans: None
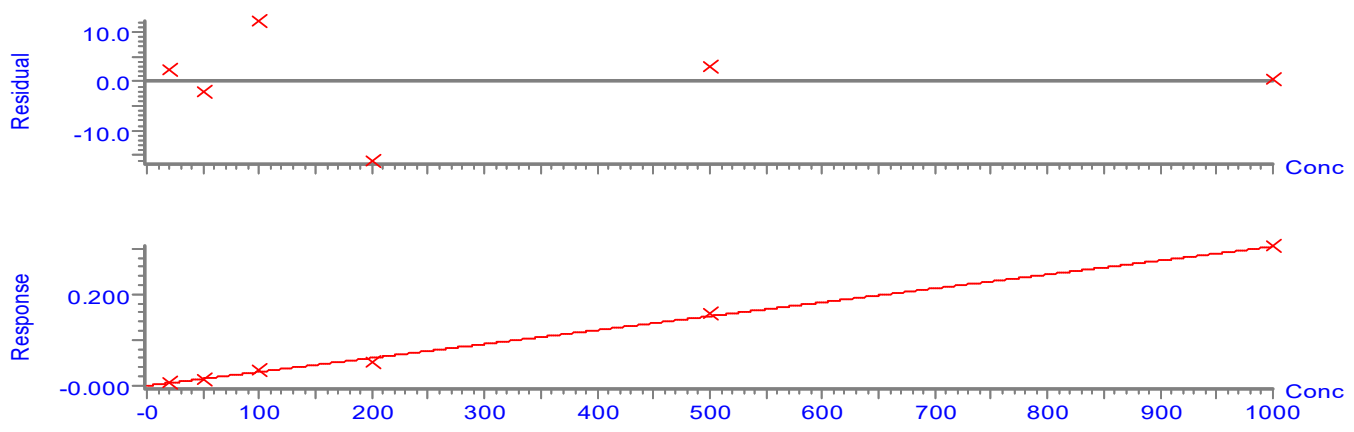

(B)
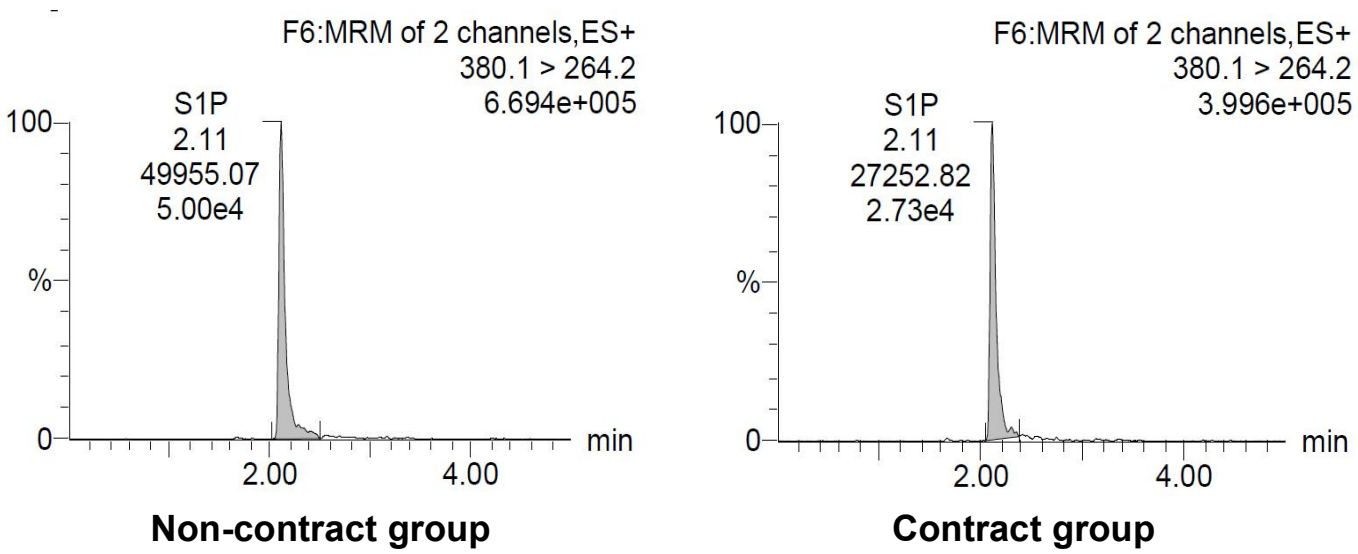

(C)

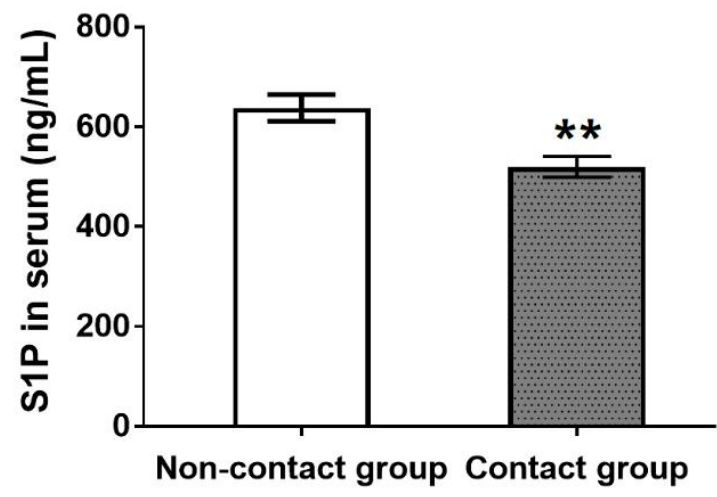

Figure2. The content of S1P in serum of acrylamide contact group and non-contact group were determined by LC-MS/MS. (A) Standard curve of S1P; (B) (C) Comparison of S1P content in serum of acrylamide contact group and non-contact group. Data are expressed as mean $\pm \mathrm{SD}$ ( $\mathrm{n}=30$ per group). ${ }^{* *} p<0.01$ versus the non-contact group. 
(A)

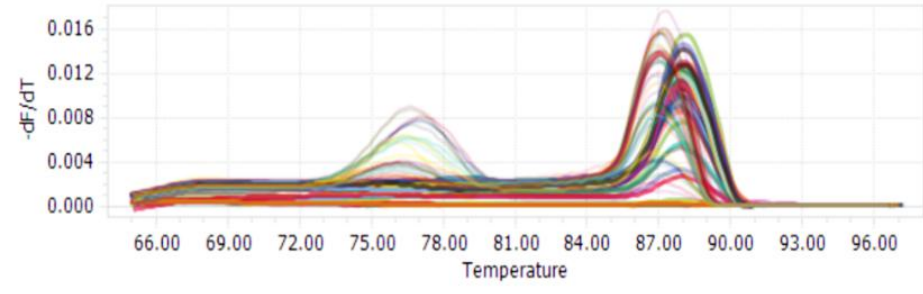

(B)

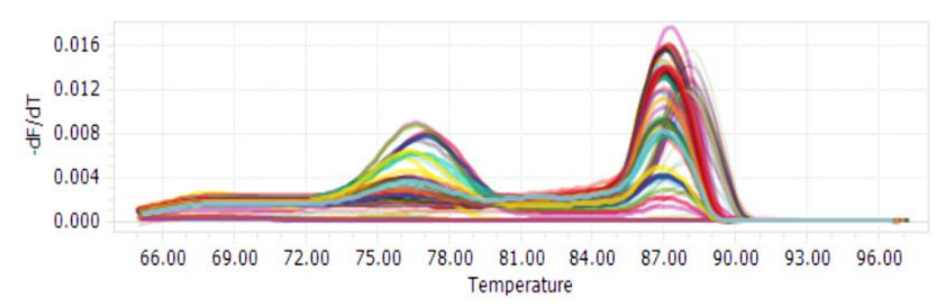

(C)

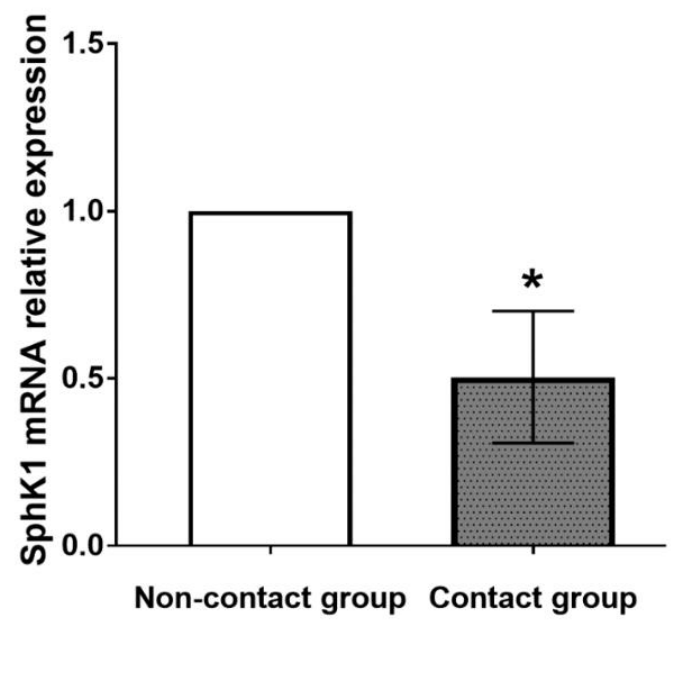

Figure 3. The relative expression level of SphK1 mRNA in whole blood of acrylamide contact group and non-contact group was determined by RT-qPCR. (A) RT-qPCR was used to determine the SphK1 gene expression melting curve in blood; (B) RT-qPCR was used to determine the internal reference gene expression melting curve in blood; (C) Comparison of relative expression levels of SphK1 mRNA in blood of acrylamide contact group and non-contact group. Data are expressed as mean $\pm \mathrm{SD}$ ( $\mathrm{n}=30$ per group). ${ }^{*} p<0.05$ versus the non-contact group. 
(A)

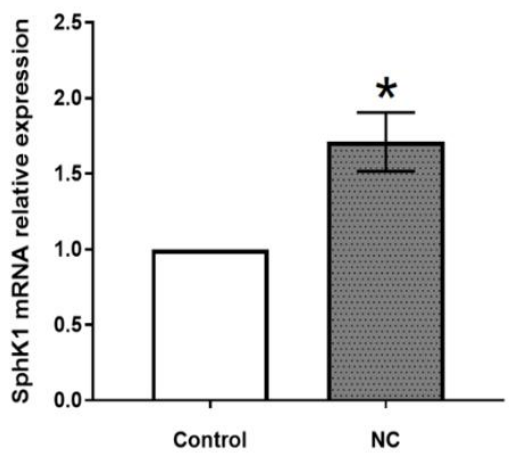

(B)

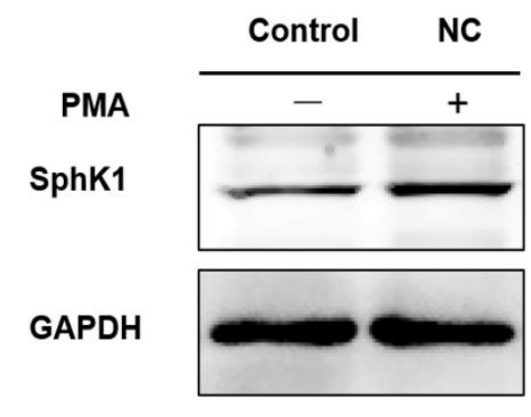

(C) SphK1/GAPDH

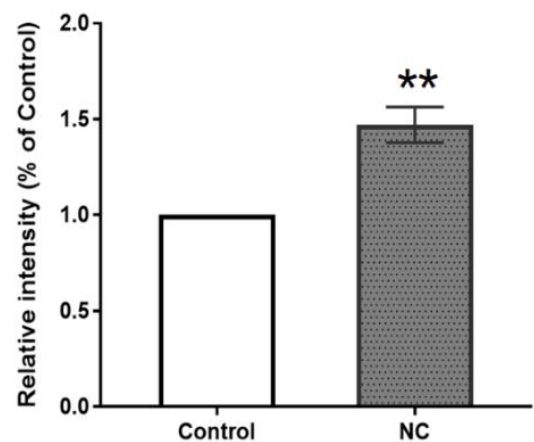

Figure 4. Determination of SphK1 activation efficiency in SH-SY5Y cells on PMA. (A) The relative expression of SphK1 mRNA in SH-SY5Y cells was determined by RT-qPCR; (B) (C) The relative expression of SphK1 protein in SH-SY5Y cells was determined by Western blot. Data are expressed as mean \pm SD ( $n=3$ per group). ${ }^{*} p<0.05,{ }^{* *} p<0.01$ versus the control group. 
(A)

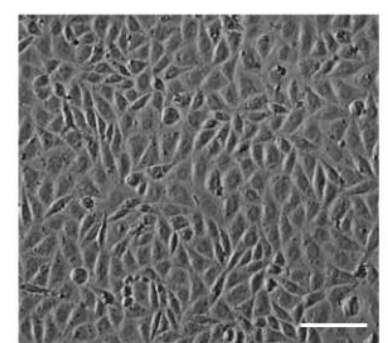

NC

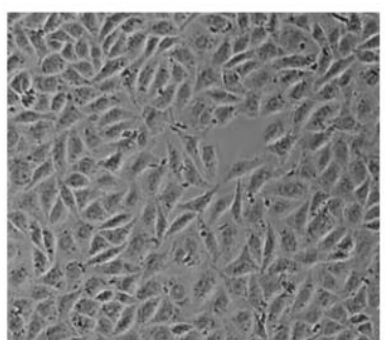

$1.25 \mathrm{mM} A C R+P M A$

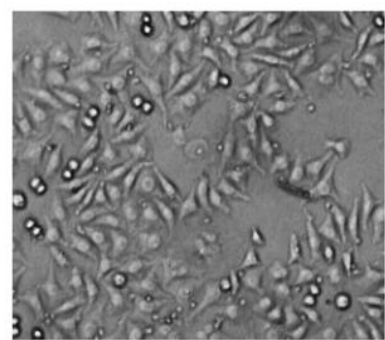

$1.25 \mathrm{mM}$ ACR

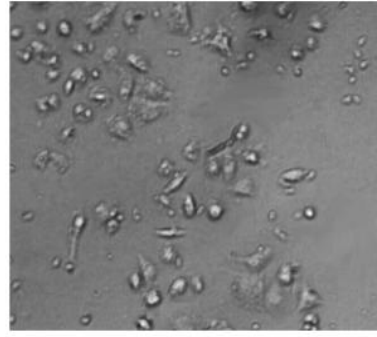

2.5mM ACR+PMA

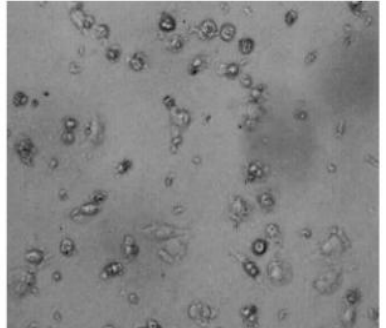

2.5mM ACR

(B)

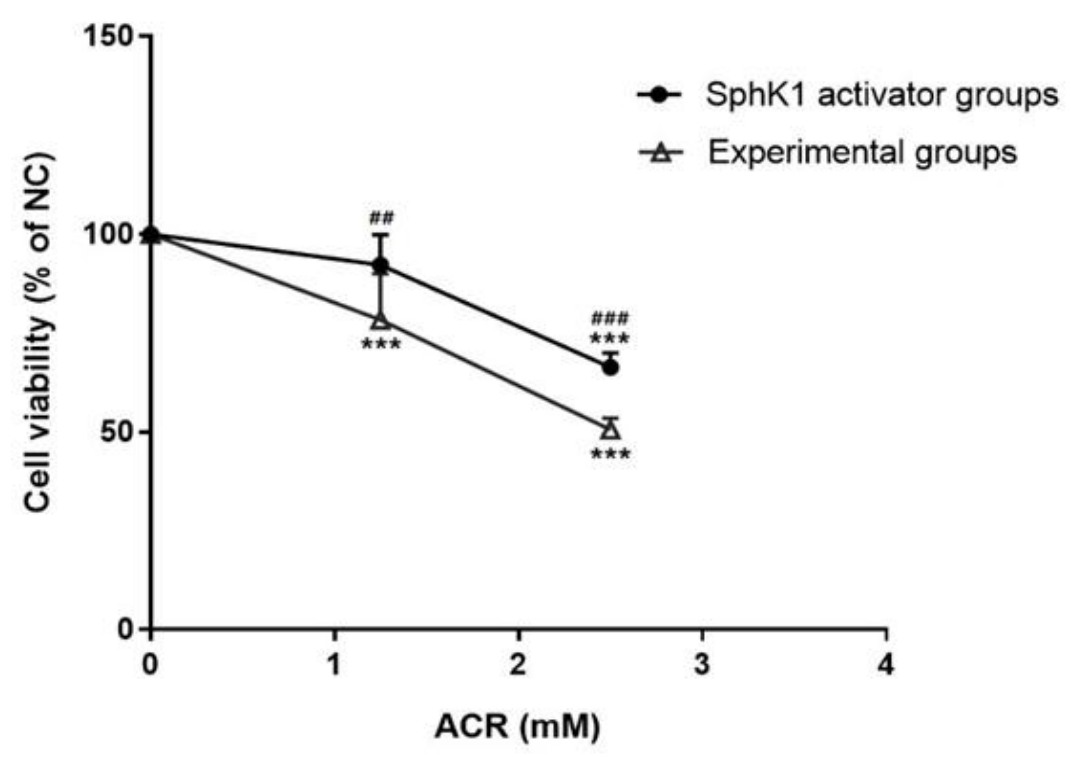

Figure 5. Experiment groups and SphK1 activator groups induced cytotoxicity in SH-SY5Y cells. (A) Cell morphology was observed under a microscope, scale bar: $100 \mu \mathrm{m}$; (B) Cell viability was determined by CCK-8 assay as preciously described in cells treated with Experiment groups and SphK1 activator groups for 24h. Data are expressed as mean $\pm \mathrm{SD}$ ( $\mathrm{n}=6$ per group). ${ }^{* * *} p<0.001$ versus the $\mathrm{NC}$ group, ${ }^{\#} p<0.01,{ }^{\# \#} p<0.001$ versus the same concentration experimental group. 
(A)

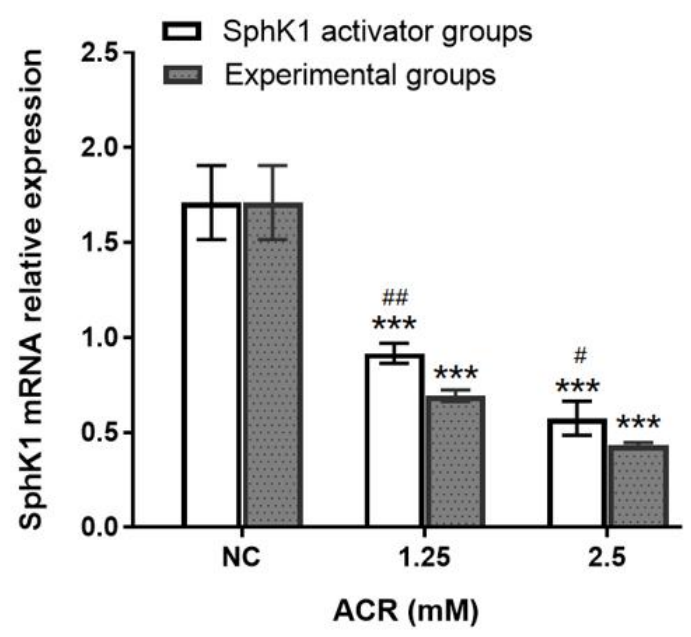

(B)

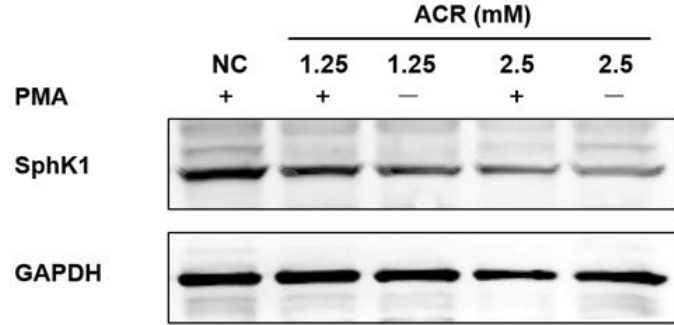

SphK1/GAPDH

(C)

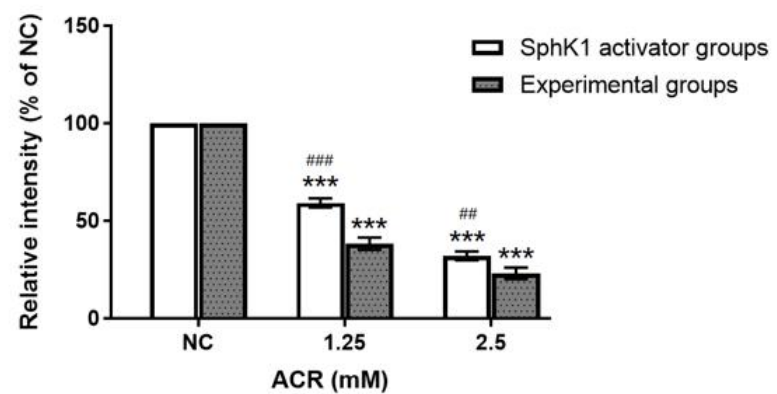

Figure 6. Expression of SphK1 in ACR exposed SH-SY5Y cells. (A) The relative expression of SphK1 mRNA in SH-SY5Y cells was determined by RT-qPCR; (B) (C) The relative expression of SphK1 protein in SH-SY5Y cells was determined by Western blot. Data are expressed as mean \pm SD ( $\mathrm{n}=3$ per group). ${ }^{* * *} p<0.001$ versus the NC group; ${ }^{\#} p<0.05,{ }^{\#} p<0.01,{ }^{\#} p<0.001$ versus the same concentration experimental group. 
(A)

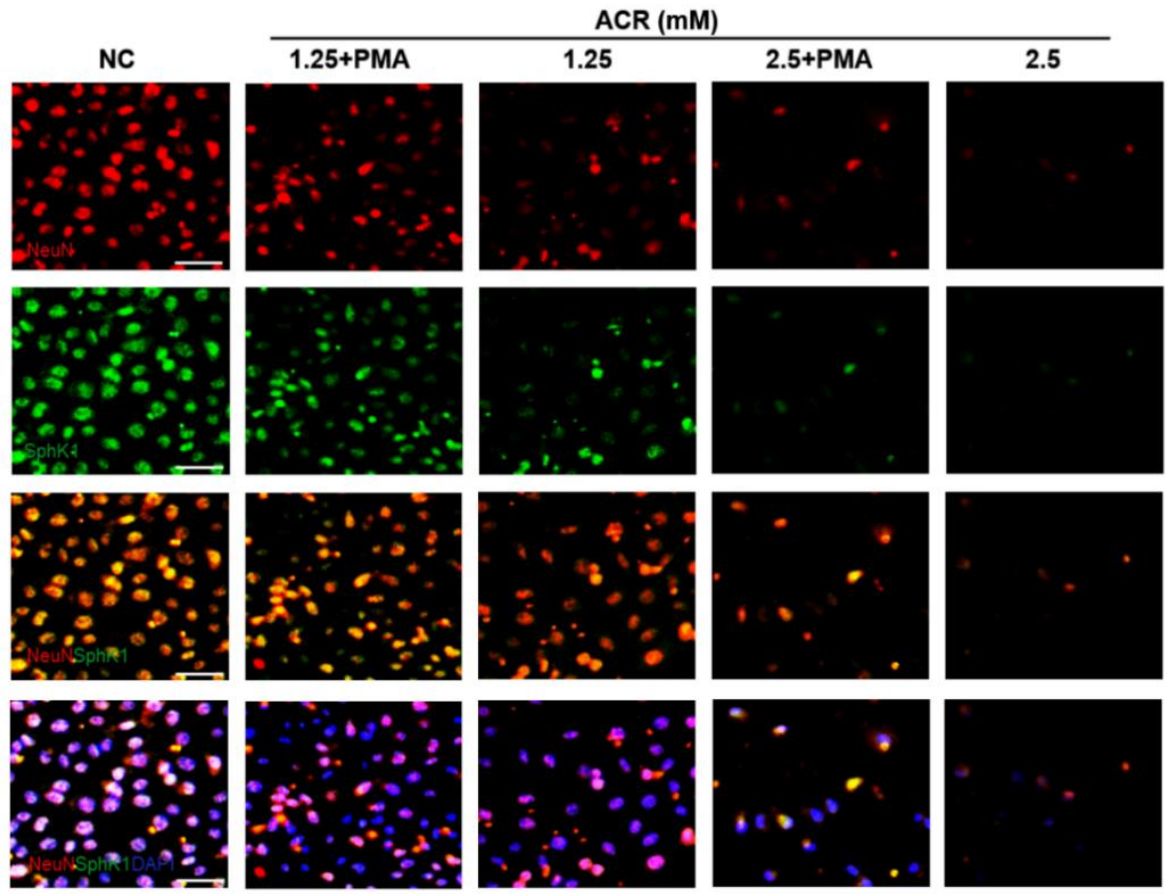

(B)

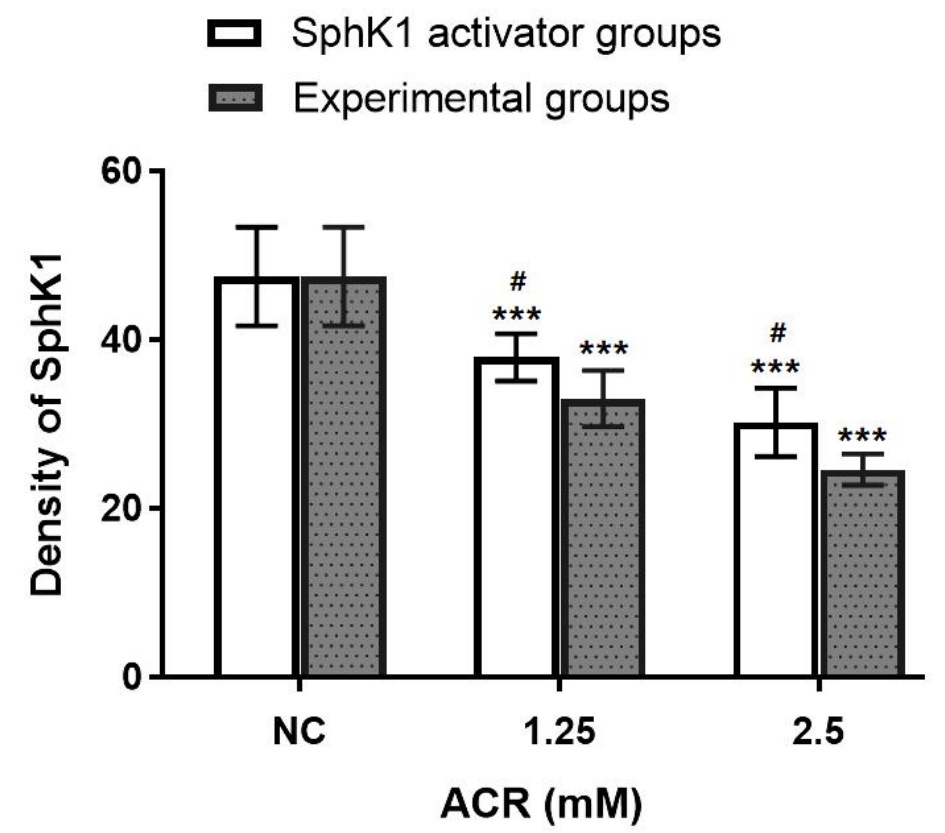

Figure 7. Multiple immunofluorescence staining was used to observe the changes of SphK1 expression after ACR exposure. (A) Specific immunofluorescence staining image SphK1(green) merged neuron (NeuN, red). Scale bars: $100 \mu \mathrm{m}$; (B) Analysis of the optical density of SphK1 (green). ${ }^{* * *} p<0.001$ versus the NC group; ${ }^{*} p<0.05$ versus the same concentration experimental group. 

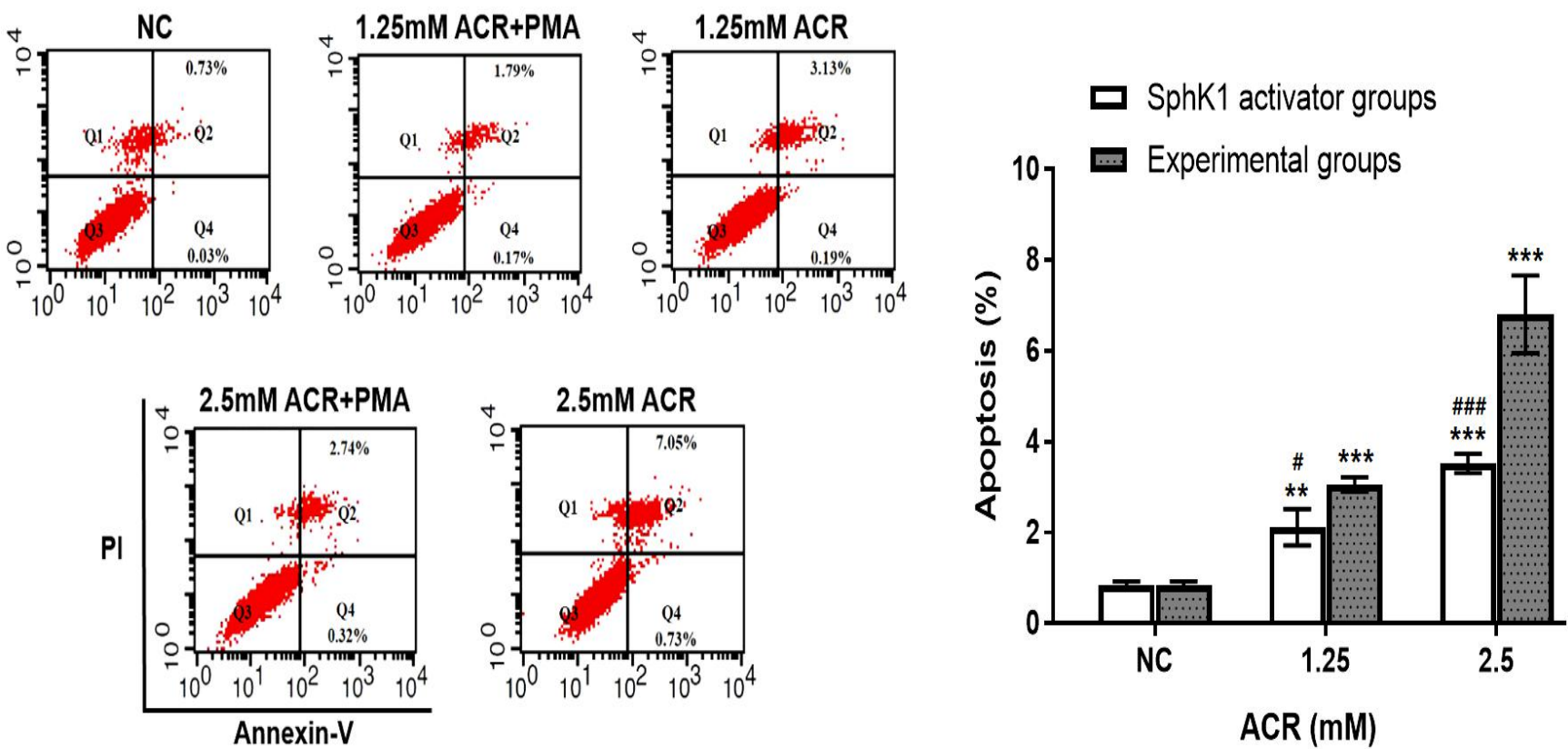

Figure 8. Proportions of living and apoptotic cells in the Sphk1 activator groups and the experimental groups were detected by flow cytometry analysis using annexin V-FITC/PI test. Living cells were unlabeled with annexin V/PI (Q3), whereas early apoptotic cells were labeled with annexin V (Q4). Cells showing annexin and PI double labeling (Q2) represent those that have already died through apoptosis. Ten thousand cells were analyzed in each sample. Percentages of total apoptotic cells based on the total cell population analyzed were determined. Data are expressed as mean $\pm \mathrm{SD}$ ( $\mathrm{n}=3$ per group). ${ }^{* *} p<0.01,{ }^{* * *} p<0.001$ versus the $\mathrm{NC}$ group, ${ }^{\#} p<0.05,{ }^{\# \#} p<0.001$ versus the same concentration experimental group. 


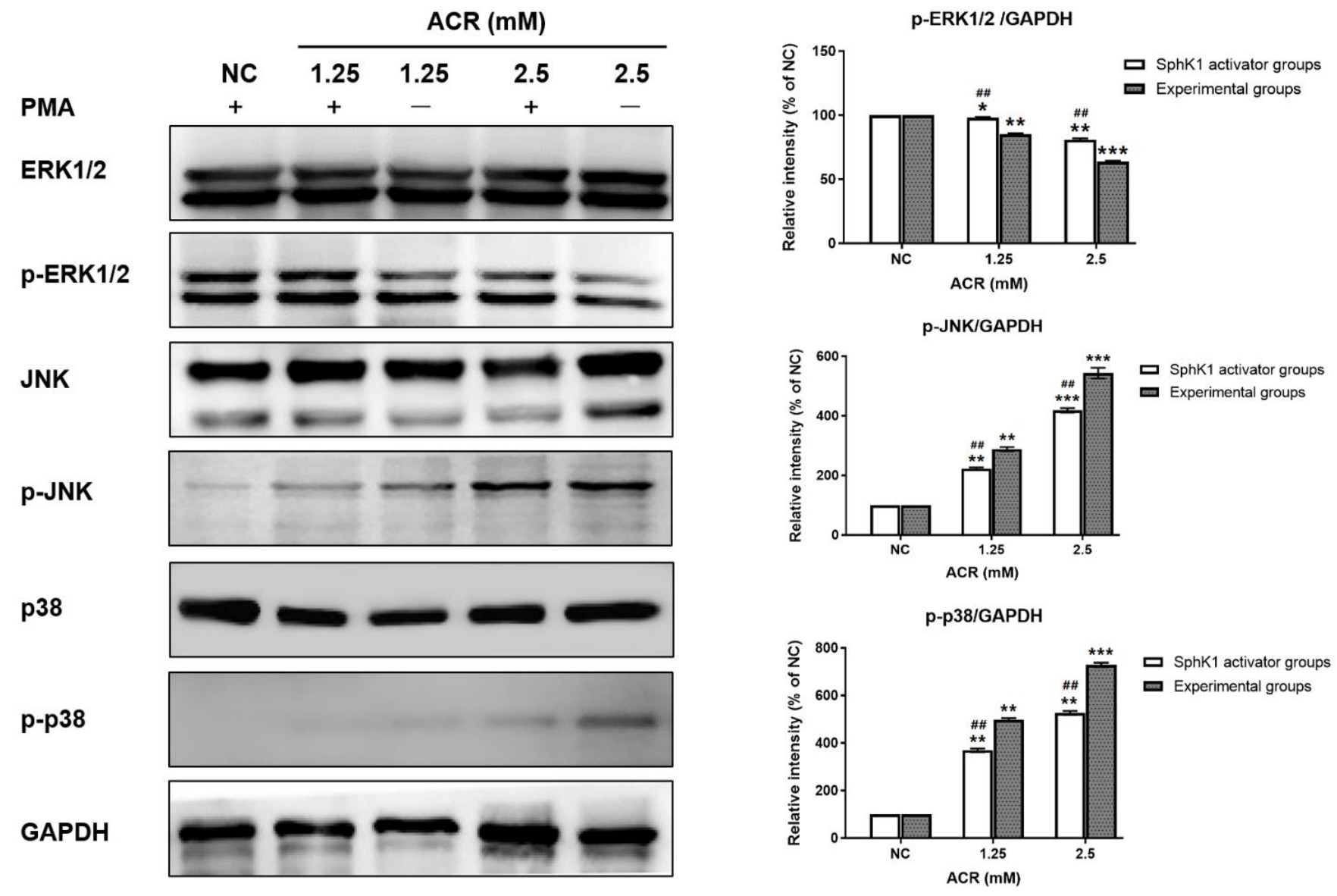

Figure 9. The treatment was conducted for 24 hours according to the experimental grouping. Protein extracts were used to determine the expression levels of ERK1/2, p-ERK1/2, JNK, p-JNK, p38 and p-p38 proteins using Western blot analysis. Data are expressed as mean $\pm \mathrm{SD}$ (n=3 per group). ${ }^{*} p<0.05,{ }^{* *} p<0.01,{ }^{* * *} p<0.001$ versus the $\mathrm{NC}$ group; ${ }^{\#} p<0.01$ versus the same concentration experimental group. 
Figures

(A)

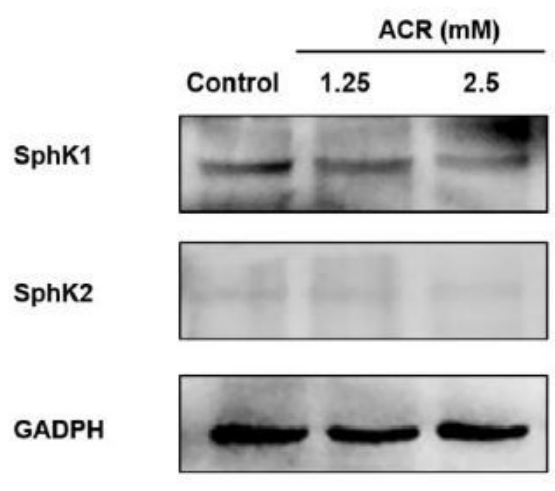

(B)

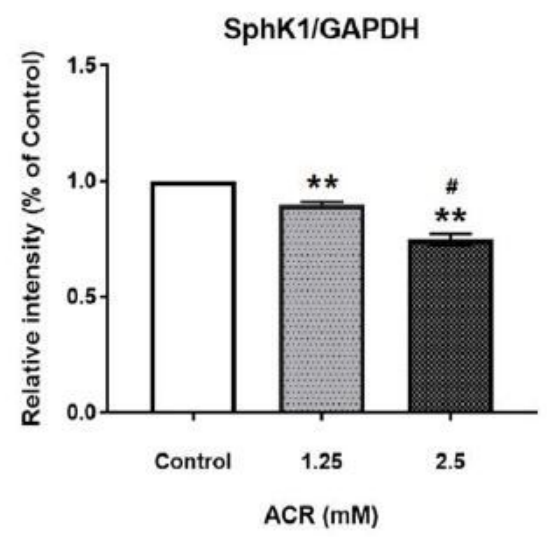

(C)

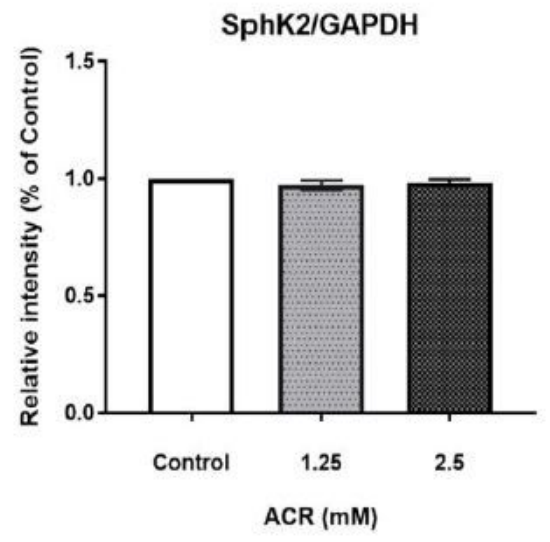

\section{Figure 1}

Western blot was used to determine the protein expression of SphK1 and SphK2 in SH-SY5Y cells exposed to ACR. (A) Protein expression of SphK1 and SphK2 in ACR-infected SH-SY5Y cells; (B) (C) Relative expression levels of SphK1 and SphK2 proteins in ACR-infected SH-SY5Y cells. Data are expressed as mean \pm SD ( $n=3$ per group). ${ }^{\star \star} p<0.01$ versus the control group, $\# p<0.05$ versus the $1.25 \mathrm{mM}$ group. 
(A)

Compound name: S1P
Correlation coemclent: $\mathrm{r}-0.997543, \mathrm{rm} 2-0.995092$

Calloration curve: $0.000305049 * x+-0.000370314$

Response type: Internal Std (Ref 4 ), Area * (IS Conc. / Is Area)

Curve type: Linear, Origin: Exclude, Welghting: 1/x Avds trans: None
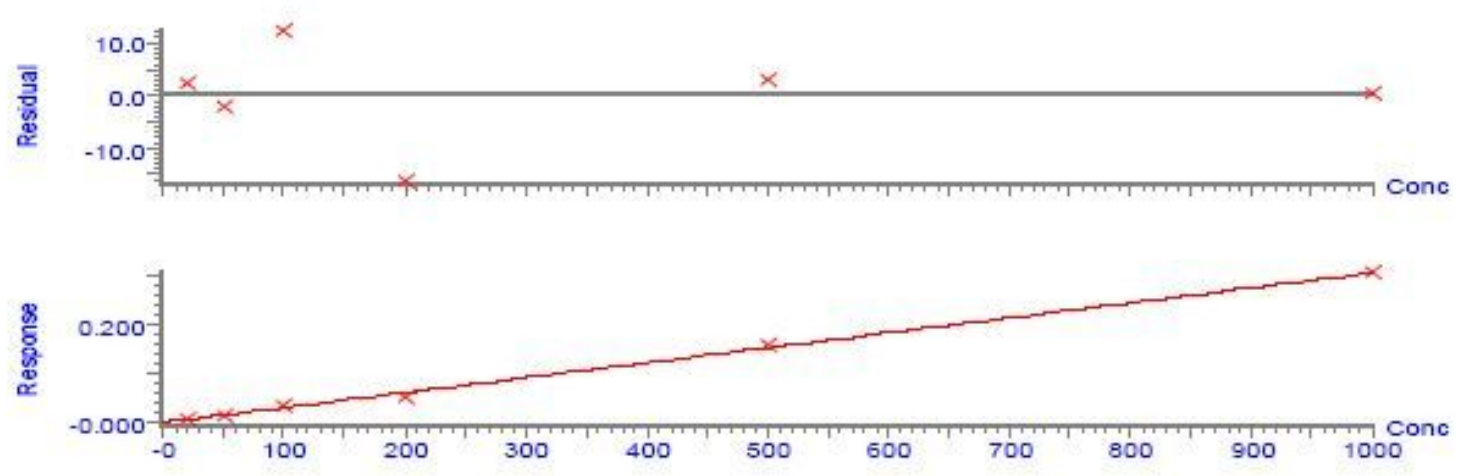

(B)

F6:MRM of 2 channels, ES+

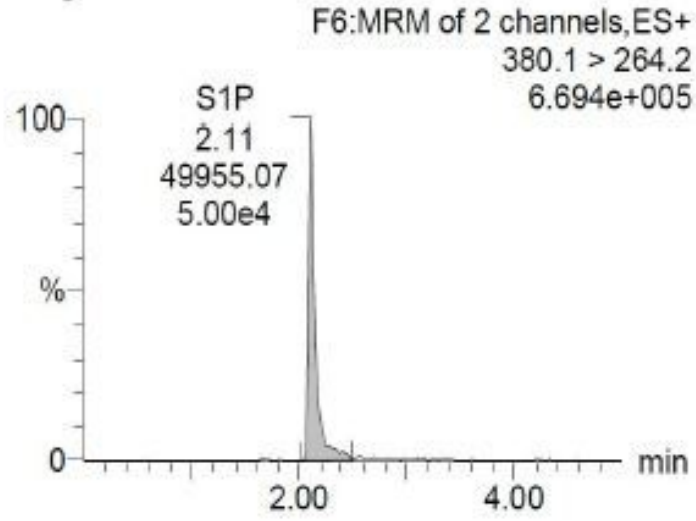

Non-contract group

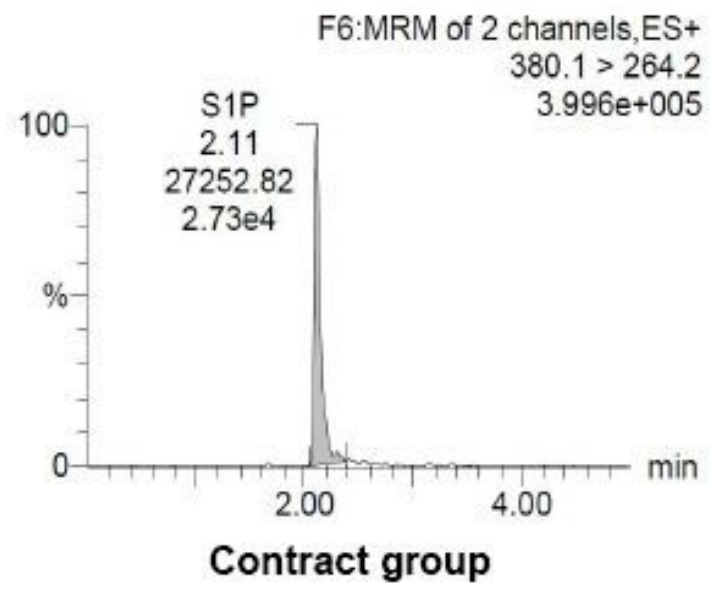

(C)

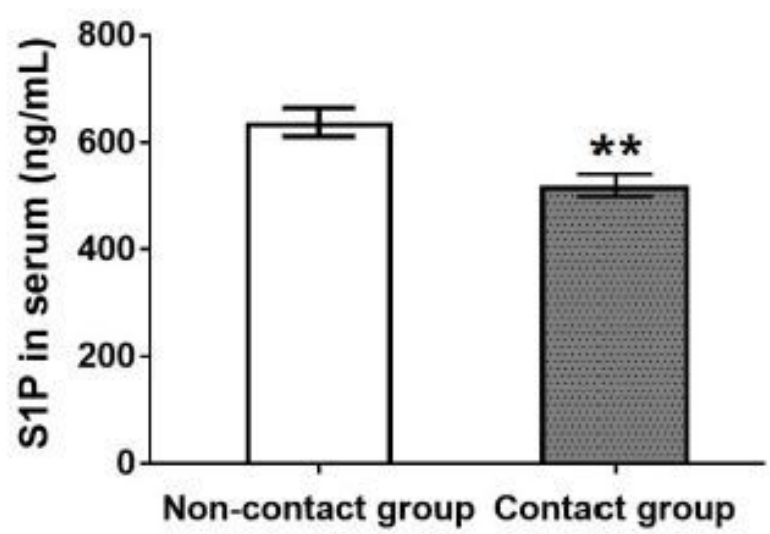

Figure 2

The content of S1P in serum of acrylamide contact group and non-contact group were determined by LCMS/MS. (A) Standard curve of S1P; (B) (C) Comparison of S1P content in serum of acrylamide contact group and non-contact group. Data are expressed as mean \pm SD ( $n=30$ per group). ${ }^{\star \star} p<0.01$ versus the non-contact group. 
(A)

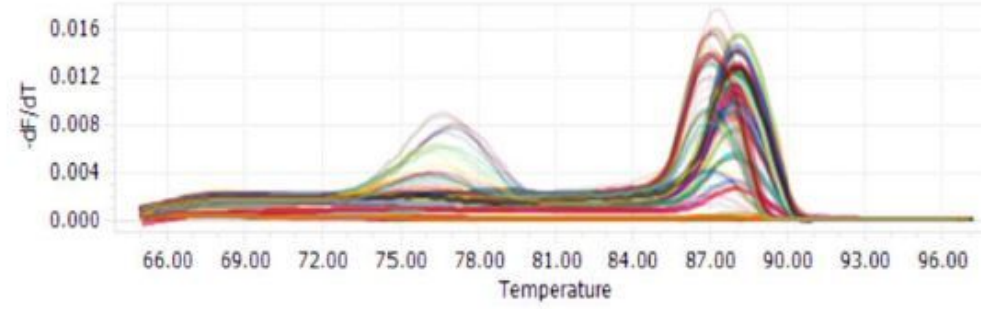

(B)

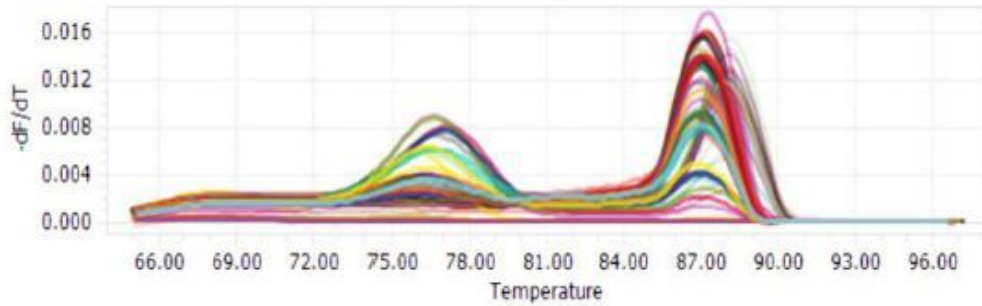

(C)

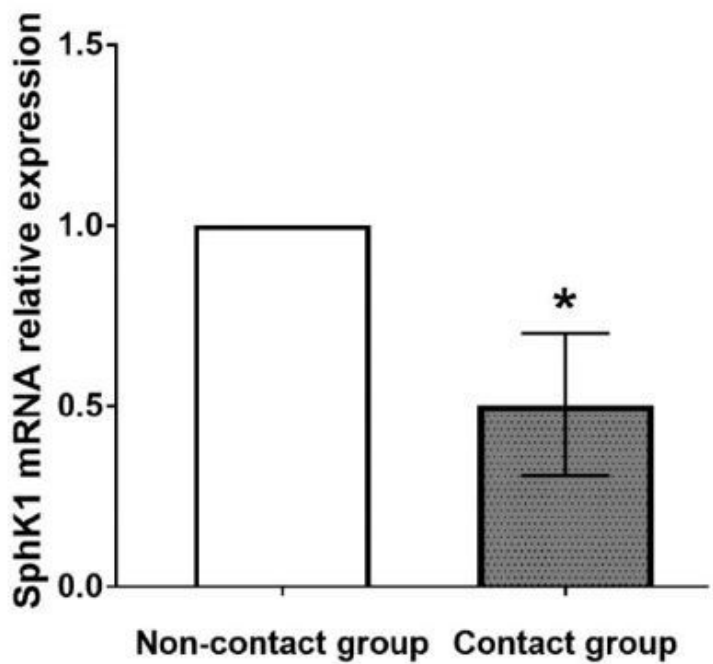

\section{Figure 3}

The relative expression level of SphK1 mRNA in whole blood of acrylamide contact group and noncontact group was determined by RT-qPCR. (A) RT-qPCR was used to determine the SphK1 gene expression melting curve in blood; (B) RT-qPCR was used to determine the internal reference gene expression melting curve in blood; (C) Comparison of relative expression levels of SphK1 mRNA in blood of acrylamide contact group and non-contact group. Data are expressed as mean $\pm S D$ ( $n=30$ per group). ${ }^{*} p<0.05$ versus the non-contact group.

(A)

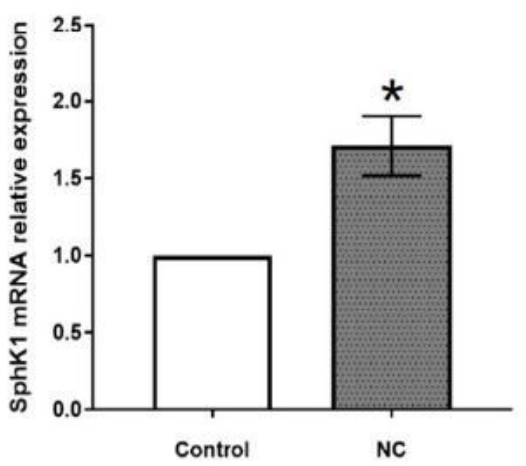

(B)

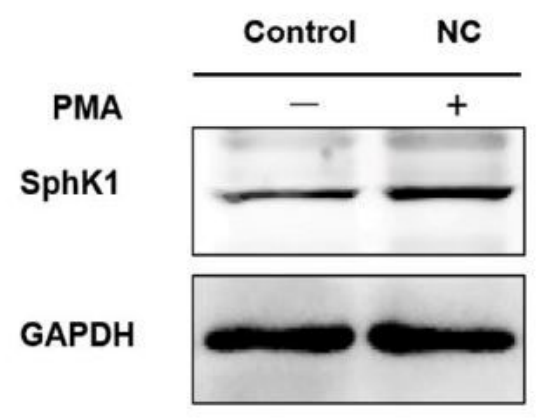

(C) SphK1/GAPDH

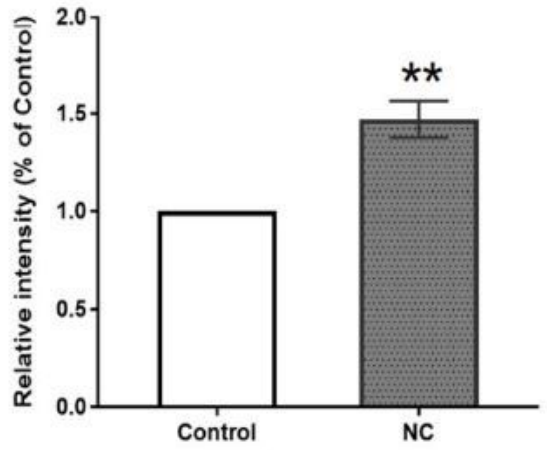

\section{Figure 4}

Determination of SphK1 activation efficiency in SH-SY5Y cells on PMA. (A) The relative expression of SphK1 mRNA in SH-SY5Y cells was determined by RT-qPCR; (B) (C) The relative expression of SphK1 
protein in SH-SY5Y cells was determined by Western blot. Data are expressed as mean \pm SD ( $n=3$ per group). ${ }^{*} p<0.05,{ }^{* *} p<0.01$ versus the control group.

(A)

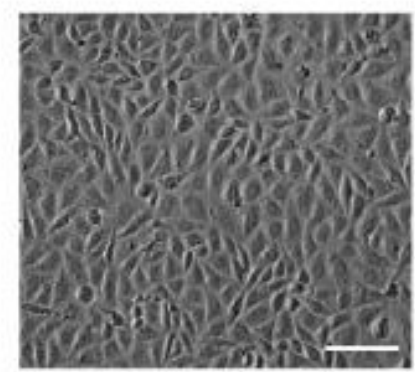

NC

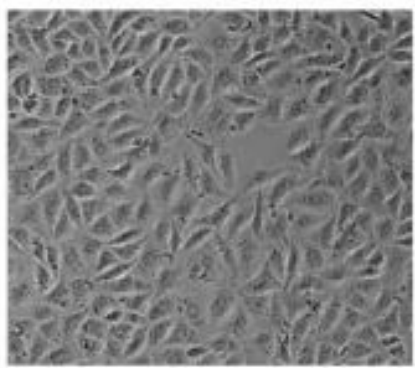

$1.25 \mathrm{mM}$ ACR+PMA

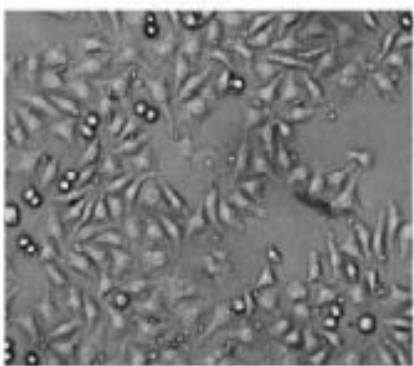

$1.25 \mathrm{mM}$ ACR

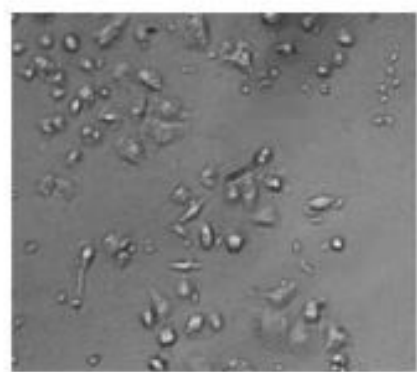

2.5mM ACR+PMA

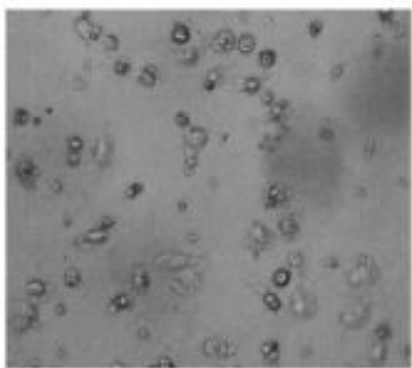

2.5mM ACR

(B)

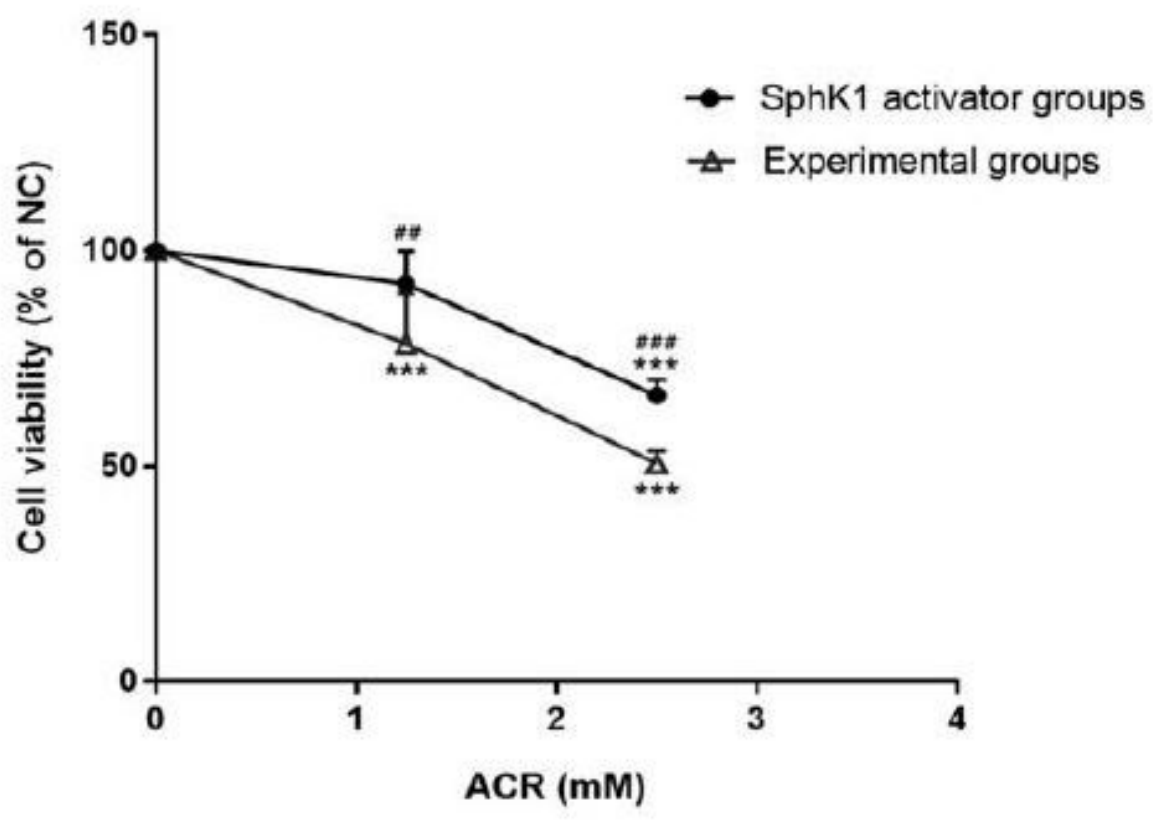

Figure 5

Experiment groups and SphK1 activator groups induced cytotoxicity in SH-SY5Y cells. (A) Cell morphology was observed under a microscope, scale bar: $100 \mu \mathrm{m}$; (B) Cell viability was determined by CCK-8 assay as preciously described in cells treated with Experiment groups and SphK1 activator groups 
for $24 \mathrm{~h}$. Data are expressed as mean \pm SD ( $n=6$ per group). ${ }^{\star \star \star} p<0.001$ versus the NC group, \#\#p<0.01, \#\#\#p<0.001 versus the same concentration experimental group.

(A)

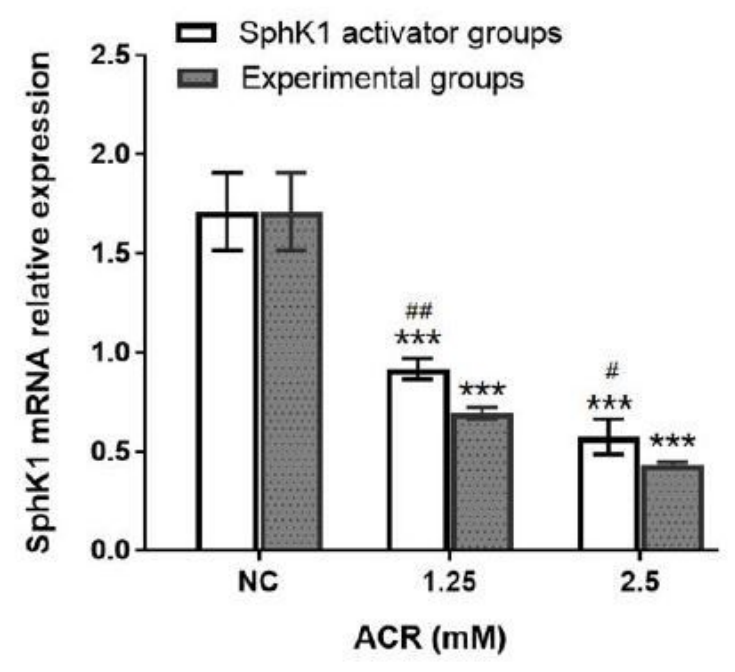

(B)

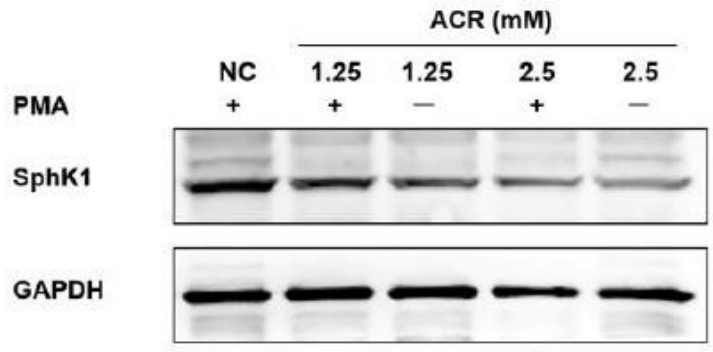

SphK1/GAPDH

(C)

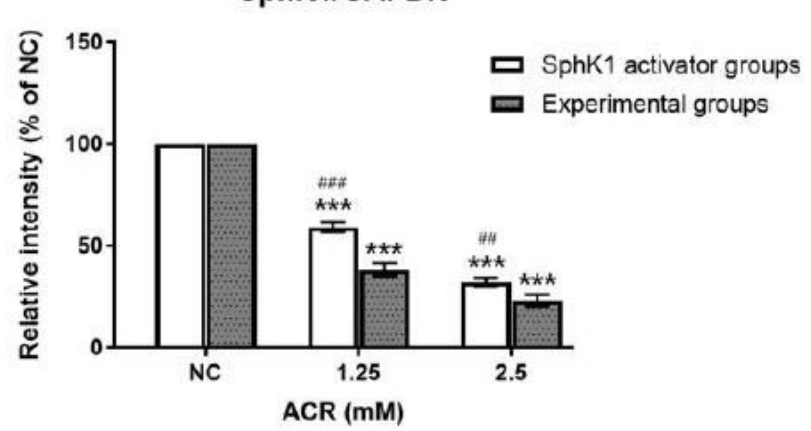

\section{Figure 6}

Expression of SphK1 in ACR exposed SH-SY5Y cells. (A) The relative expression of SphK1 mRNA in SHSY5Y cells was determined by RT-qPCR; (B) (C) The relative expression of SphK1 protein in SH-SY5Y cells was determined by Western blot. Data are expressed as mean $\pm S D$ ( $n=3$ per group). ${ }^{\star \star \star} p<0.001$ versus the NC group; $\# p<0.05, \# \# p<0.01, \# \# \# p<0.001$ versus the same concentration experimental group. 
(A)

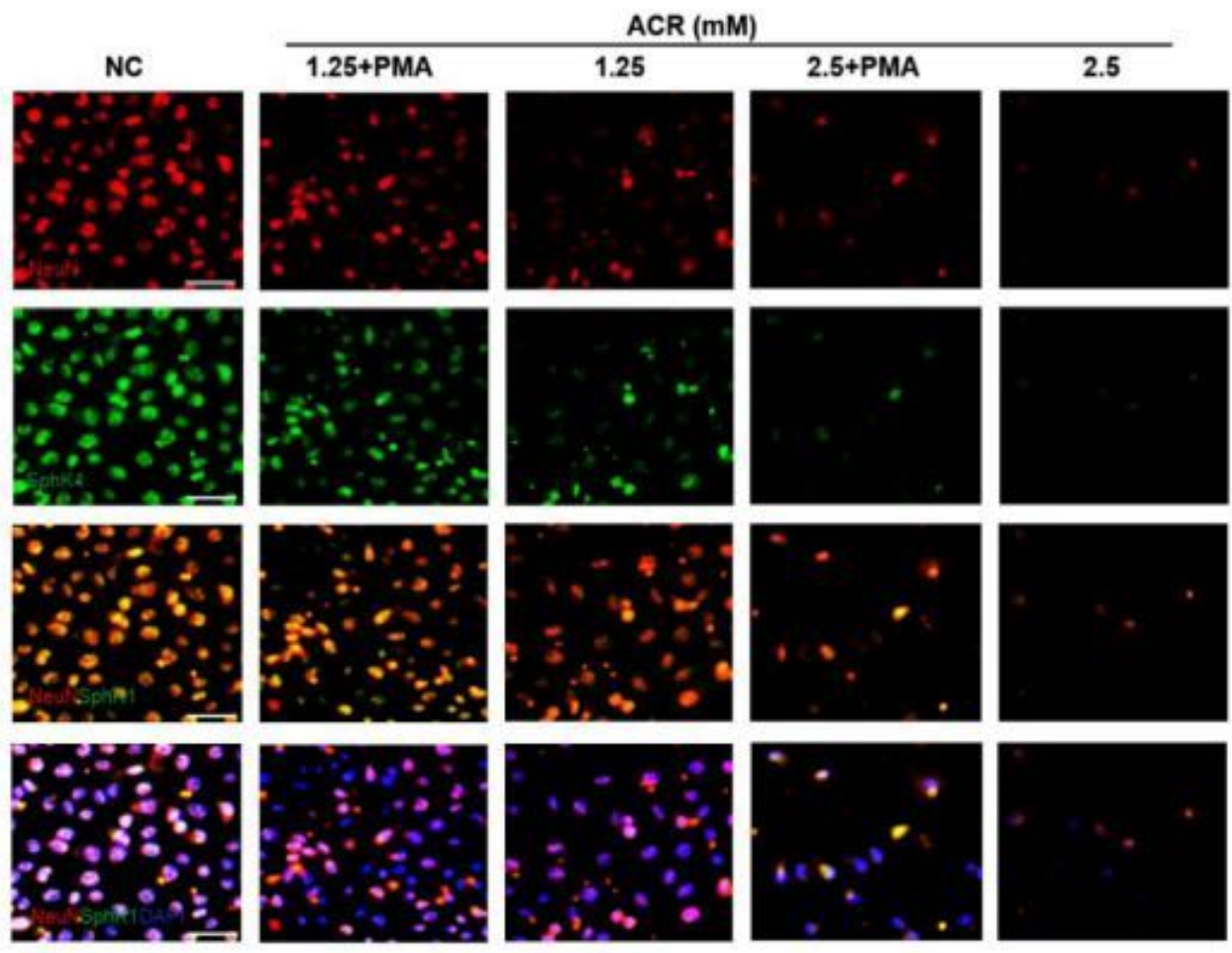

(B)

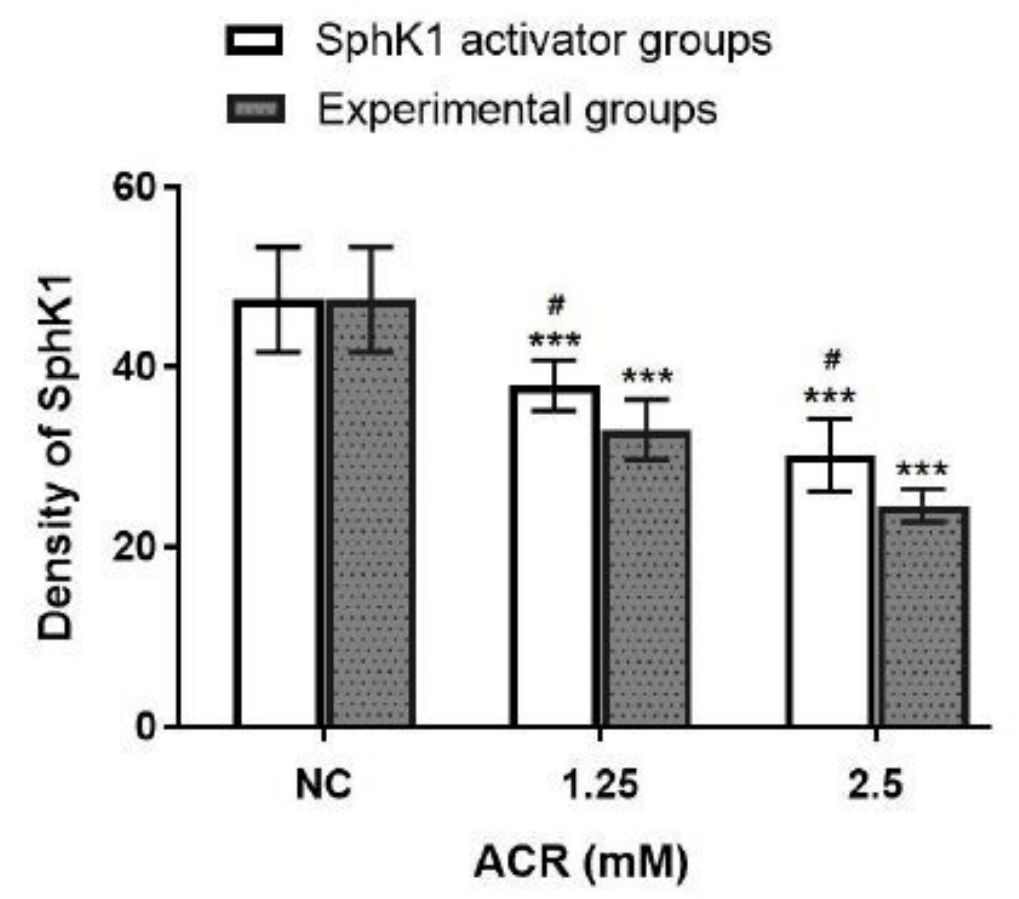

Figure 7

Multiple immunofluorescence staining was used to observe the changes of SphK1 expression after ACR exposure. (A) Specific immunofluorescence staining image SphK1 (green) merged neuron (NeuN, red). Scale bars: $100 \mu \mathrm{m}$; (B) Analysis of the optical density of SphK1 (green). ${ }^{\star \star *} \mathrm{p}<0.001$ versus the NC group; $\# p<0.05$ versus the same concentration experimental group. 

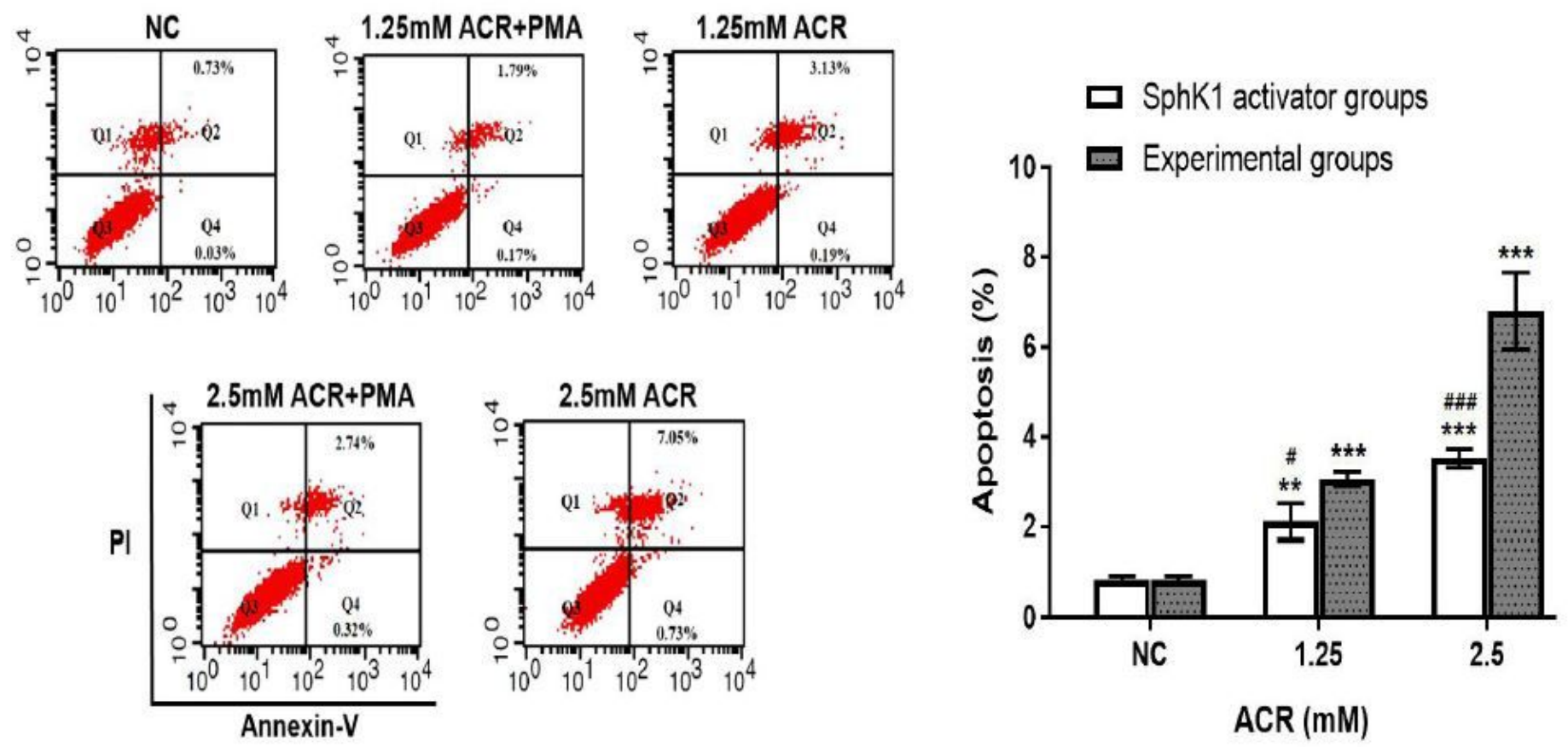

Figure 8

Proportions of living and apoptotic cells in the Sphk1 activator groups and the experimental groups were detected by flow cytometry analysis using annexin V-FITC/PI test. Living cells were unlabeled with annexin V/PI (Q3), whereas early apoptotic cells were labeled with annexin V (Q4). Cells showing annexin and PI double labeling (Q2) represent those that have already died through apoptosis. Ten thousand cells were analyzed in each sample. Percentages of total apoptotic cells based on the total cell population analyzed were determined. Data are expressed as mean \pm SD ( $n=3$ per group). ${ }^{*} p<0.01,{ }^{*}{ }^{*} p<0.001$ versus the NC group, $\# p<0.05$, \#\#\#p<0.001 versus the same concentration experimental group. 


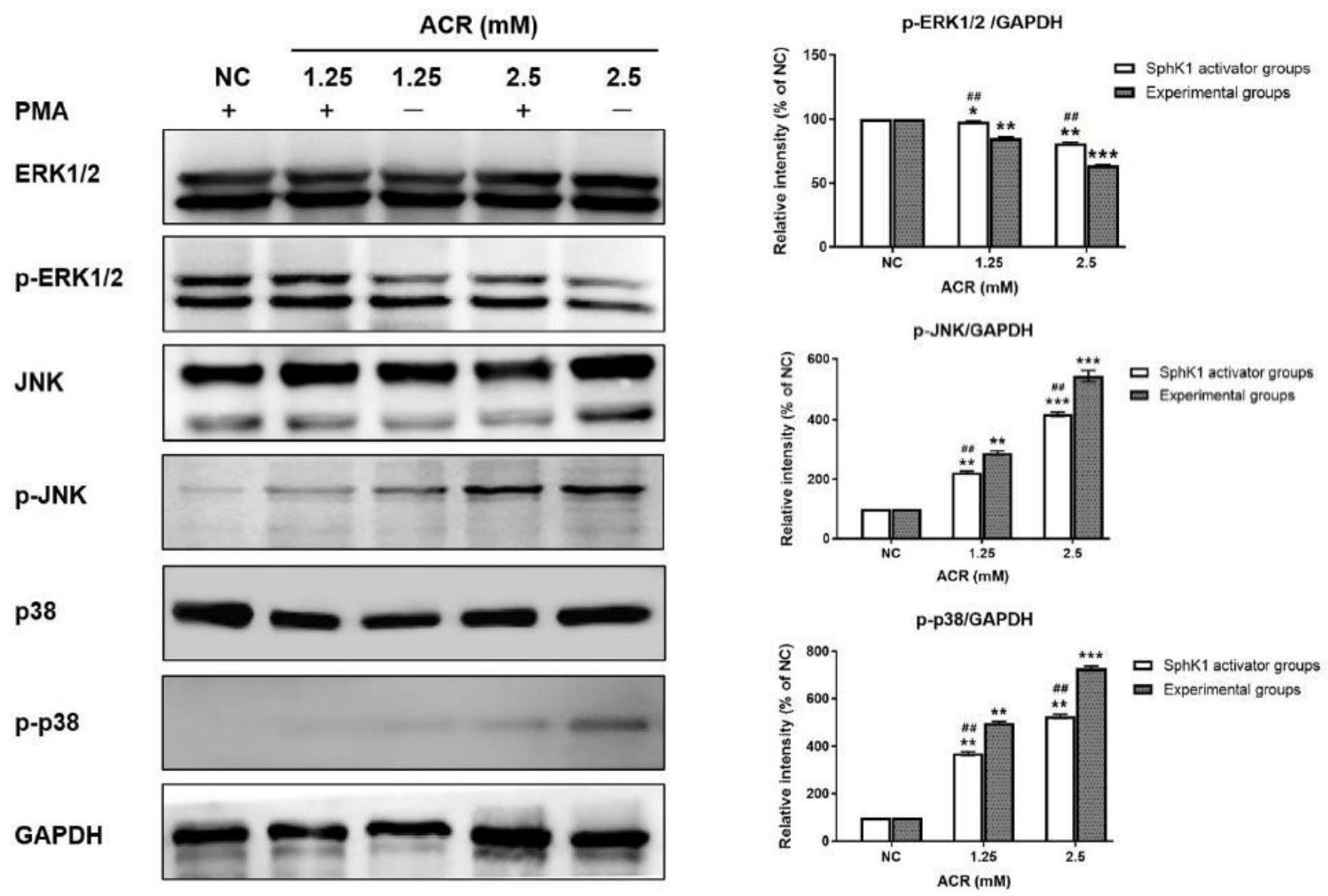

Figure 9

The treatment was conducted for 24 hours according to the experimental grouping. Protein extracts were used to determine the expression levels of ERK1/2, p-ERK1/2, JNK, p-JNK, p38 and p-p38 proteins using Western blot analysis. Data are expressed as mean \pm SD ( $n=3$ per group). ${ }^{\star} p<0.05,{ }^{\star \star} p<0.01,{ }^{\star \star *} p<0.001$ versus the NC group; \#\#p<0.01 versus the same concentration experimental group.

\section{Supplementary Files}

This is a list of supplementary files associated with this preprint. Click to download.

- SupplementaryTable.docx 